Hors-série $n^{\circ} 8 \mid 2015$

Au seuil du cloître : la présence des laïcs (hôtelleries, bâtiments d'accueil, activités artisanales et de services) entre le Ve et le XII ${ }^{\mathrm{e}}$ siècle

Le monastère face aux laïques au haut Moyen Âge : lieux de culte secondaires et accueil aux limites de l'espace monastique dans le contexte italien

\title{
Eleonora Destefanis
}

\section{(2) OpenEdition}

Journals

\section{Édition électronique}

URL : https://journals.openedition.org/cem/13599

DOI : 10.4000/cem.13599

ISSN : 1954-3093

Éditeur

Centre d'études médiévales Saint-Germain d'Auxerre

\section{Référence électronique}

Eleonora Destefanis, « Le monastère face aux lä̈ques au haut Moyen Âge : lieux de culte secondaires et accueil aux limites de l'espace monastique dans le contexte italien », Bulletin du centre d'études médiévales d'Auxerre / BUCEMA [En ligne], Hors-série nº 8 | 2015, mis en ligne le 16 novembre 2015, consulté le 02 mars 2023. URL : http://journals.openedition.org/cem/13599; DOI : https://doi.org/ $10.4000 /$ cem.13599

Ce document a été généré automatiquement le 2 mars 2023.

\section{(i)(2)}

Creative Commons - Attribution - Pas d'Utilisation Commerciale - Partage dans les Mêmes Conditions 4.0 International - CC BY-NC-SA 4.0

https://creativecommons.org/licenses/by-nc-sa/4.0/ 
Le monastère face aux laïques au haut Moyen Âge : lieux de culte secondaires et accueil aux limites de l'espace monastique dans le contexte italien $^{1}$

Eleonora Destefanis

Monastères et accueil : problèmes de terminologie à la lumière des sources italiennes 
$1 \mathrm{Au}$ sein du plus vaste domaine de l'hospitalité et de l'assistance au haut Moyen Âge ${ }^{2}$, la place occupée par les monastères, prévue d'ailleurs dans les règles monastiques ${ }^{3}$, est essentielle. Pourtant, plusieurs questions restent ouvertes à partir de la terminologie employée par les sources. Elle se présente, en effet, souvent de façon ambigüe: plusieurs définitions - xenodochia, hospitalia, ou, notamment pour le cas de Rome, diaconiae - sont utilisées, auxquelles il est toujours difficile de faire correspondre une réalité structurelle concrète. L'historiographie récente a mis

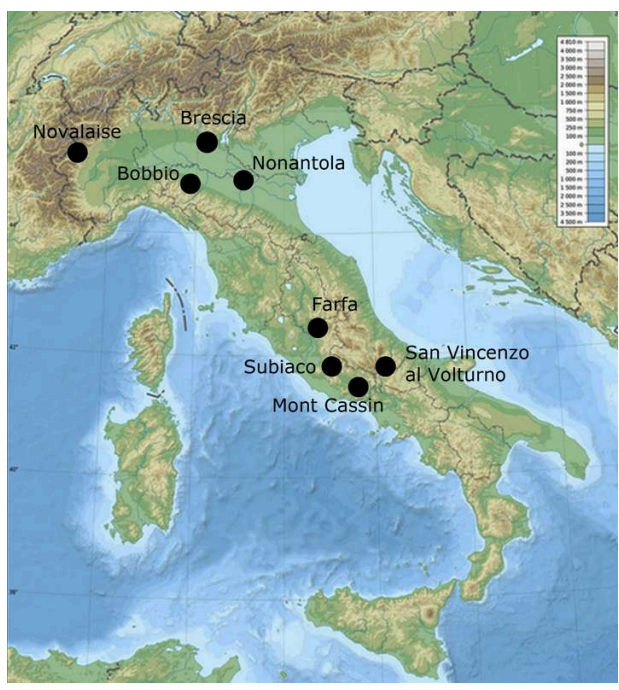
en évidence la polysémie de ces définitions, qui peuvent chacune évoquer des établissements charitables bien différents, dans une perspective aussi bien institutionnelle que matérielle ; par contre, plusieurs termes peuvent être employés dans des sources contemporaines, y compris dans le même texte, pour faire allusion à la même réalité.

2 On remarque, tout d'abord, l'association parfois assez étroite entre monasterium et xenodochium : c'est le cas, entre autres, du monastère Sainte-Marie in Organo à Vérone, qui est qualifié dans un plaid du 845 de monasterio seo sinodochio sancte Marie. Cette ambiguïté subsiste d'ailleurs au fil du document, qui parle d'un avocat dit parfois du monasterium, parfois de sinodochio, bien qu'il s'agisse évidemment du même homme, représentant la même institution et agissant ad partem monasterii de sinodochio sancte Marie $^{4}$. Il ne s'agit pas d'une locution isolée dans la documentation de cette période, qui montre pourtant des spécificités régionales, voir locales. Dans le Breviarium Ecclesiae Ravennatis, rédigé dans la seconde moitié $\mathrm{du} \mathrm{x}^{\mathrm{e}}$ siècle, on trouve des expressions telles que monasterium Sancte Marie qui vocatur Exenadochio ou de iure monasterii senodochii Sancte Mariae cata portam Sancti Laurencii ${ }^{5}$. Dans le contexte particulier qui est celui de Ravenne, le monasterium indique très souvent un petit édifice cultuel, un oratoire, sans qu'aucune communauté monastique n'y soit forcément rattachée. En effet, Agnellus, au $\mathrm{IX}^{\mathrm{e}}$ siècle, qualifiait de monasteria les capellae seu sacella circa basilicas aedificata, in quibus defunctorum corpora sepeliebantur, cum ea intra basilicas ipsas sepelire nondum liceret ${ }^{6}$.

3 À Rome, d'autre part, à côté du plus commun xenodochium, dans le dernier quart du $\mathrm{VII}^{\mathrm{e}}$ siècle apparaît le terme diaconia, et, un peu plus tardivement, hospitale, dans un cadre où l'assistance aux pèlerins, mais surtout aux indigents de la ville, est de plus en plus contrôlée par l'Église. D’après une étude récente de Hendrick Dey, il semble possible d'envisager dans les sources romaines une différence dans les rôles de ces institutions ${ }^{7}$, bien que les xenodochia comme les diaconiae soient des entités monastiques. L'auteur met l'accent sur l'expression monasteriis diaconiae, citée à plusieurs reprises dans le Liber Pontificalis dès les années quatre-vingt du $\mathrm{VII}^{\mathrm{e}}$ siècle, qui serait à interpréter comme la présence de communautés monastiques chargées de l'assistance, qui agiraient dans le cadre d'une idée d'un monachisme centré sur la vita activa dans le saeculum au lieu d'une vie contemplative au sein du claustrum ${ }^{8}$. Le problème, encore une fois, touche à la signification que l'on attribue au terme 
monasterium, qui semble connaître au fil du haut Moyen Âge des déclinaisons différentes, même dans la perspective spécifique de l'assistance et de l'hospitalité.

Au-delà des cas assez particuliers de Ravenne et - pour des raisons différentes - de Rome, un certain nombre de difficultés subsistent sur l'identité et la nature des monasteria, mais aussi des xenodochia, notamment ceux qui sont attachés aux premiers. Thomas Tsabó a souligné qu'il s'agit peut-être, en partie, d'un faux problème: ces xenodochia, mentionnés de façon plus au moins ambiguë en association avec les monastères, ne seraient pas à identifier comme des personnalités juridiques différentes, mais simplement comme des lieux d'accueil rattachés à des monastères ${ }^{9}$.

5 Si cette proposition est tout à fait probable dans maints cas, les sources suggèrent une réalité sans doute plus nuancée. La documentation relative aux villes toscanes de l'époque lombarde, notamment Lucques et Pistoia, à côté des monastères principaux pourvus d'une structure communautaire élargie et organisée selon des principes hiérarchiques, montre l'existence d'un certain nombre de tout petites communautés, qualifiées pour la plupart de monasteria ou ecclesiae, constituées souvent de personnes appartenant à la même famille ayant décidé de se consacrer à la vie religieuse, tout en restant dans leur propre maison ${ }^{10}$. Une église, normalement fondée par un membre de la famille, représente le centre spirituel de ces ensembles, pour lesquels la charité et l'hospitalité - surtout axées sur les repas livrés aux pauvres et aux peregrini - semblent essentielles.

Les documents mobilisent un lexique varié, démontrant clairement la polysémie des termes. En 764, par exemple, un certain Anspaldus dispose par testament que sa parente Rattruda, qualifiée de Dei ancilla, aura le droit, après sa mort, de gouverner l'eclesia et monasterium Sainte-Marie, qu'il a fondés sur le terrain où se trouve sa maison - in fundamento de casa habitationis nostrae -, dans la ville de Lucques, ainsi que de donner mandat à un prêtre ou un diacre (rector), qui, in ipso Dei monasterio et in casa predicte eclesiae, s'occupera, trois jours par semaine, de servir le repas à douze pauperes et peregrini, sicut et in alia senodochia pauperes ad mensa pascere videtur ${ }^{11}$.

7 Le problème de la gestion et de la direction des structures destinées à l'accueil au sein de ces monasteria est également à souligner. Dans la plupart des cas, le rector, chargé du soulagement de ces catégories spécifiques d'hôtes, est un prêtre, qui se trouve parfois qualifié d'abbas: un terme qui, comme on le sait d'après les études de Luce Pietri et d'Hélène Noizet, peut être employé sans aucune implication «monastique » (au sens propre) ${ }^{12}$, même si dans la documentation concernant ces monasteria/xenodochia on le trouve associé à des contextes où il est effectivement question d'une congregatio des monachi ${ }^{13}$.

8 Face à ces scénarios très variés, aussi bien du point de vue institutionnel que matériel, je me bornerai ici aux monastères au sens propre du terme. En effet, le problème des édifices cultuels au sein des espaces d'accueil n'a pas été l'objet, jusqu'à présent, d'une étude de synthèse, même si Émile Lesne, en 1943, dans le sixième volume de l'Histoire de la propriété ecclésiastique en France, avait déjà attiré l'attention sur la "chapelle particulière » associée à l'hôtellerie des pauvres ${ }^{14}$. 


\section{Églises secondaires et accueil au sein de l'espace monastique}

9 Le sujet étant assez vaste et voulant privilégier une approche qui croise les sources écrites avec celles archéologiques, je ne prendrai pas en compte - sauf dans un cas assez particulier - les structures d'accueil (les xenodochia/hospitalia) créées par les monastères sur leurs territoires, dans des lieux plus ou moins éloignés du centre abbatial, sur lequel, en revanche, je concentrerai mon attention.

Les témoignages écrits citent pour plusieurs monastères la présence d'espaces d'accueil, mais la mention explicite d'une église rattachée au xenodochium/hospitale est très souvent indirecte. De plus, les informations concernant l'aspect matériel de cette église, ses fonctions et même sa position par rapport aux bâtiments d'accueil et au monastère dans son ensemble, sont encore plus rares ${ }^{15}$. Les sources archéologiques, pour leur part, sont elles aussi assez rares, étant donné que l'attention des fouilleurs, au moins en Italie, s'est concentrée surtout sur les abbatiales et parfois sur les édifices claustraux, en laissant souvent de côté les espaces d'accueil.

11 Les problèmes qui se posent en abordant ce thème sont en réalité multiples et touchent aussi bien aux aspects topographiques que fonctionnels. Les règles monastiques ne mentionnent pas explicitement la présence d'églises affectées à l'accueil ${ }^{16}$, tandis qu'à l'époque carolingienne le tableau devient plus riche. En particulier, les dispositions d'Aix-la-Chapelle en 816 , bien que rapportées aux communautés de chanoinesses (sanctimoniales canonice degentes), fournissent des données intéressantes démontrant la complexité de l'ensemble destiné à l'accueil: elles laissent entrevoir, en effet, à l'extérieur de l'enceinte et à la porte du monasterium puellarum, un espace où l'hospitale pauperum doit s'élever iuxta ecclesiam (...) in qua presbiteri cum ministris suis divinum explent officium, tout près de l'église - plausiblement ouverte aux usagers de l'hôpital -, affectée aux prêtres auxquels est également demandée la cura spirituelle des religieuses ${ }^{17}$.

\section{Saint-Sauveur-Sainte-Julie de Brescia}

12 Le cas du monastère féminin Saint-Sauveur-Sainte-Julie de Brescia (fig. 1), fondé par le roi lombard Didier vers le milieu du vIII ${ }^{e}$ siècle, semble bien illustrer, à cet égard, ce choix topographique. 
Fig. 1 - Localisation des monastères italiens cités dans le texte (élaboration E. Destefanis).

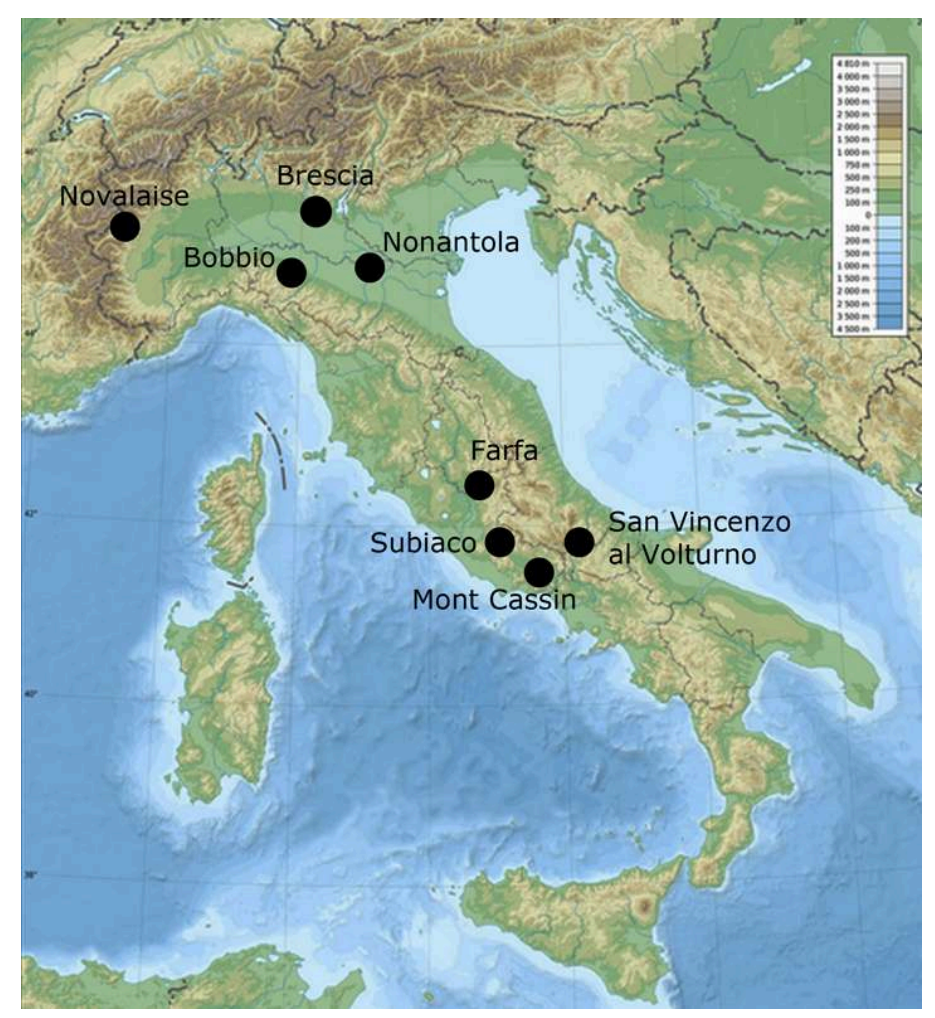

13 Cet ensemble, dont l'église de la fin de l'époque lombarde et une partie des bâtiments conventuels associés à celle-ci aujourd'hui subsistent en élévation, a été fouillé sur une surface assez étendue, ce qui a permis de reconstituer l'organisation de l'espace occupé par les moniales ${ }^{18}$.

14 L'hôpital du monastère aurait été fondé en 877 par la moniale Gisla, avec la donation de vingt-quatre lits pour les pauvres et les pèlerins ${ }^{19}$. Après cette mention, il faut attendre le début $\mathrm{du} \mathrm{XIII}^{\mathrm{e}}$ siècle pour disposer d'une documentation plus détaillée sur cette institution. À cette époque et pour tout le bas Moyen Âge, celle-ci se présente comme un ensemble assez complexe, avec une cour, un entrepôt, un réfectoire et surtout un grand bâtiment à deux étages pourvu d'un escalier, qualifié de palatium hospitalis Sancte Iulie $^{20}$.

15 Cet ensemble est probablement à situer immédiatement à l'extérieur du claustrum, vers l'ouest (fig. 2), le long de la route toujours existante qui la sépare du monastère. 
Fig. 2 - Brescia. Le quartier Saint-Sauveur-Sainte-Julie à la fin du Moyen Âge (en haut) ; reconstruction du plan du monastère à la même époque. En évidence : I'ensemble associé à I'hospitale, avec la chapelle Saint-Rémy. D'après A. BREDA, « Strutture architettoniche e fonti scritte », in R. STRADIOTTI (dir.), San Salvatore, Santa Giulia di Brescia. II monastero nella storia, Milan, 2001, p. 135.
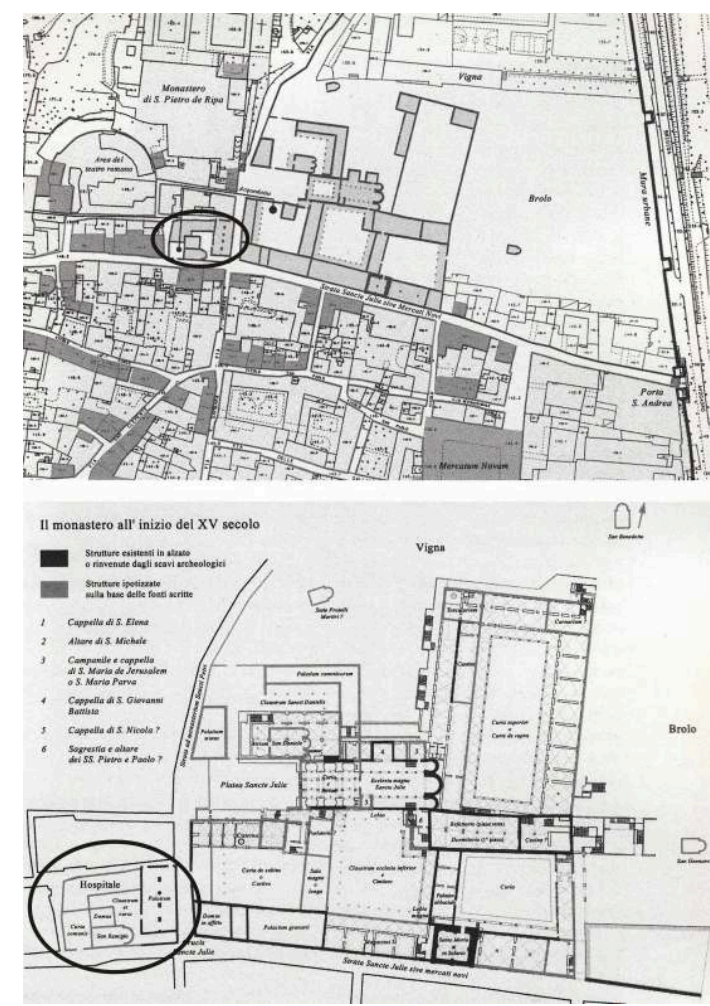

Les maçonneries anciennes ici conservées montrent au moins deux états de construction remontant à l'époque médiévale (fig. 3), dont la plus récente, attribuable $\mathrm{au} \mathrm{XII}$ siècle, se superpose à une phase plus ancienne, du haut Moyen Âge - d'après sa technique de construction -, qu'on associe unanimement au xenodochium du monastère ${ }^{21}$. 
Fig. 3 - Brescia, monastère Saint-Sauveur. Lecture stratigraphique des maçonneries de l'hospice sur via Piamarta : le $\mathrm{n}^{\circ} 1$ indique les parties du haut Moyen Âge ; d'après C. ZANI, "Lo xenodochio di S. Giulia », in C. STELLA et G. BRENTEGANI (dir.), S. Giulia di Brescia. Archeologia, arte, storia di un monastero regio dai Longobardi al Barbarossa, Brescia, 1992, p. 247.

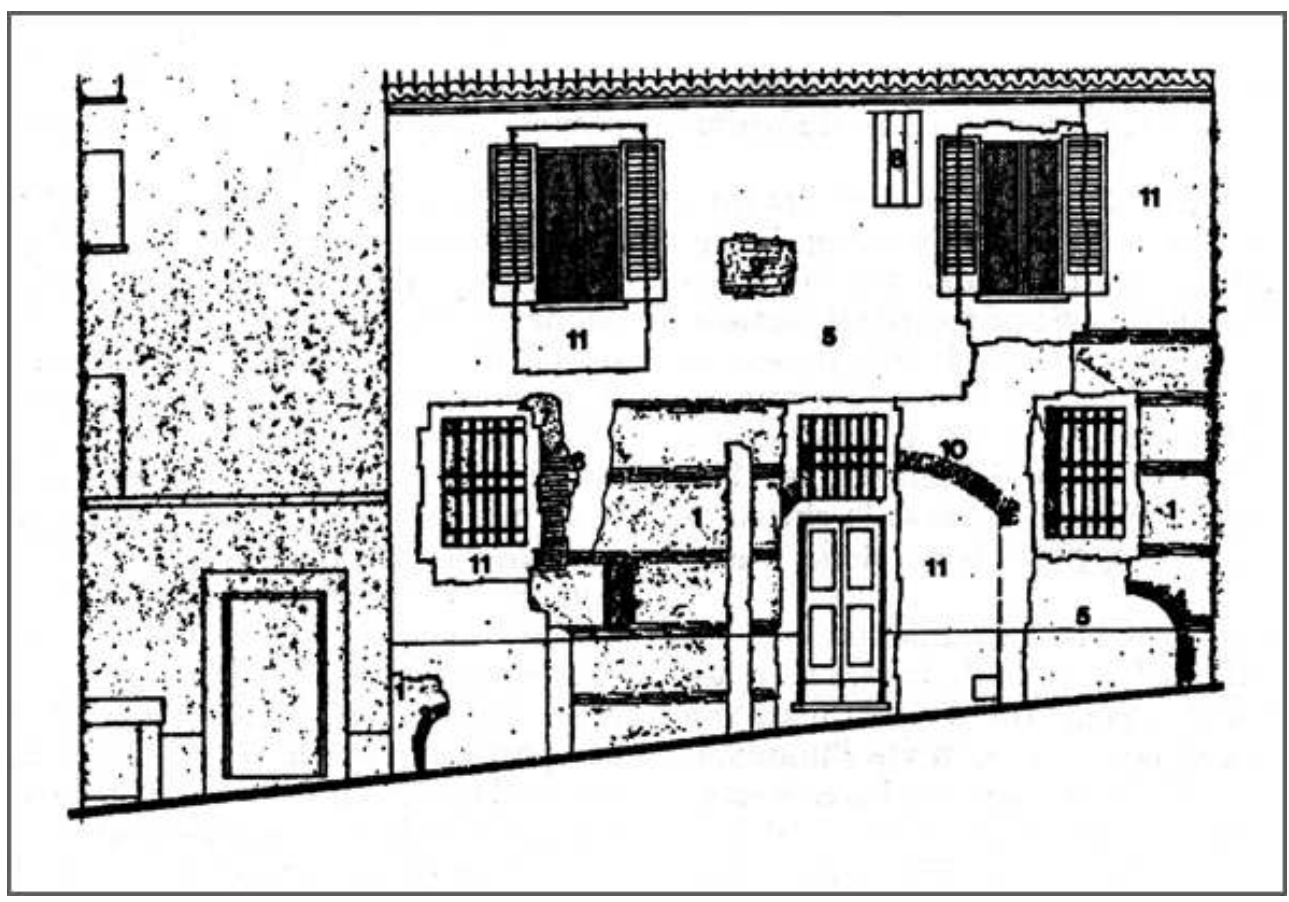

$\mathrm{Au}$ sein de ce complexe s'élevait une chapelle dédiée à saint Rémy (fig. 2), mentionnée depuis le début du $\mathrm{XII}^{\mathrm{e}}$ siècle comme située in Sanethogo (dérivation de xenodochium) et attribuée à l'époque carolingienne à cause de sa dédicace ${ }^{22}$, qui semble particulièrement bien attestée dans l'Italie du Nord à cette époque et pendant les décennies suivantes ${ }^{23}$.

Selon une hypothèse récente, au haut Moyen Âge, cet ensemble aurait eu la fonction d'hospitale nobilium, tandis que l'hospitale pauperum, également lié à l'abbaye, serait à placer à l'extérieur de la ville, tout près de l'église Saint-André et à proximité de la porte homonyme, à environ $300 \mathrm{~m}$ à l'est du monastère ${ }^{24}$.

19 À l'époque où la documentation devient plus abondante, l'institution est dirigée par une prelata ou domina hospitalis, nommée par l'abbesse et à la tête d'un groupe de convers et converses. On ne dispose pas de données pour la période précédente, bien qu'un document de 1207 relate l'investiture de la part du responsable de l'église SaintDaniel, affectée à la communauté des chanoines rattachée à l'abbaye, d'une domus dite juris ipsium ecclesie que iacet in xenodochio ${ }^{25}$. L'ensemble canonial est localisable, au moins depuis la fin du XII ${ }^{e}$ siècle, tout près de l'atrium de l'abbatiale Saint-Sauveur (immédiatement au nord) ${ }^{26}$. On ne connaît pas la date de l'institution de la communauté canoniale, même si la situation décrite par le concile d'Aix-la-Chapelle aux marges des noyaux religieux féminins - prévoyant, comme on l'a vu, une relation assez étroite entre les chanoines et le lieu d'accueil, immédiatement à l'extérieur du claustrum - laisse envisager la création d'un ensemble canonial au service des moniales et de leur xenodochium dès le haut Moyen Âge, quand l'hôpital semble attesté et qu'il est peut-être pourvu d'une chapelle.

20 Certes, le cas peut apparaître comme particulier, puisqu'il s'agit d'un important monastère féminin - donc marqué par une clôture assez stricte - et urbain, ce qui peut 
expliquer la nécessité de garder l'espace d'accueil à l'écart des espaces réservés à la communauté. Néanmoins, cet ensemble est conçu comme strictement lié à l'abbaye, faisant partie intégrante du monasterium, ce qui conduit à s'interroger encore une fois sur ce terme, notamment par rapport au problème de l'accueil et de lieux de culte liés à cette fonction.

21 Comme on vient de le rappeler, il s'agit d'une notion polysémique, qui inclut une conception spécifique de surface, d'étendue, sur laquelle s'élargit l'emprise des moines et qui peut aller bien au-delà de l'enceinte monastique stricto sensu. Le monasterium, comme l'a bien expliqué Hélène Noizet pour Saint-Martin de Tours, "correspond parfois à une auréole géographique plus étendue que les bâtiments eux-mêmes, incluant des églises, des maisons et un lieu de marché ${ }^{27}$ ». Dans le contexte français, l'église Saint-Clément (fig. 4), à laquelle était rattaché l'hospitale pauperum à l'époque carolingienne, tout en surgissant à l'extérieur de la clôture, est clairement indiquée par les sources écrites comme située in monasterio, ainsi que d'autres chapelles (cellae) qui entourent le noyau monastique, telle que Notre-Dame de l'Écrignole, à laquelle est associée la matricula ${ }^{28}$.

Fig. 4 - Tours, le quartier canonial Saint-Martin vers 850 ; d'après H. GALINIÉ (dir.), Tours antique et médiéval. Lieux de vie, temps de la ville. 40 ans d'archéologie urbaine, Tours, 2007, p. 366.

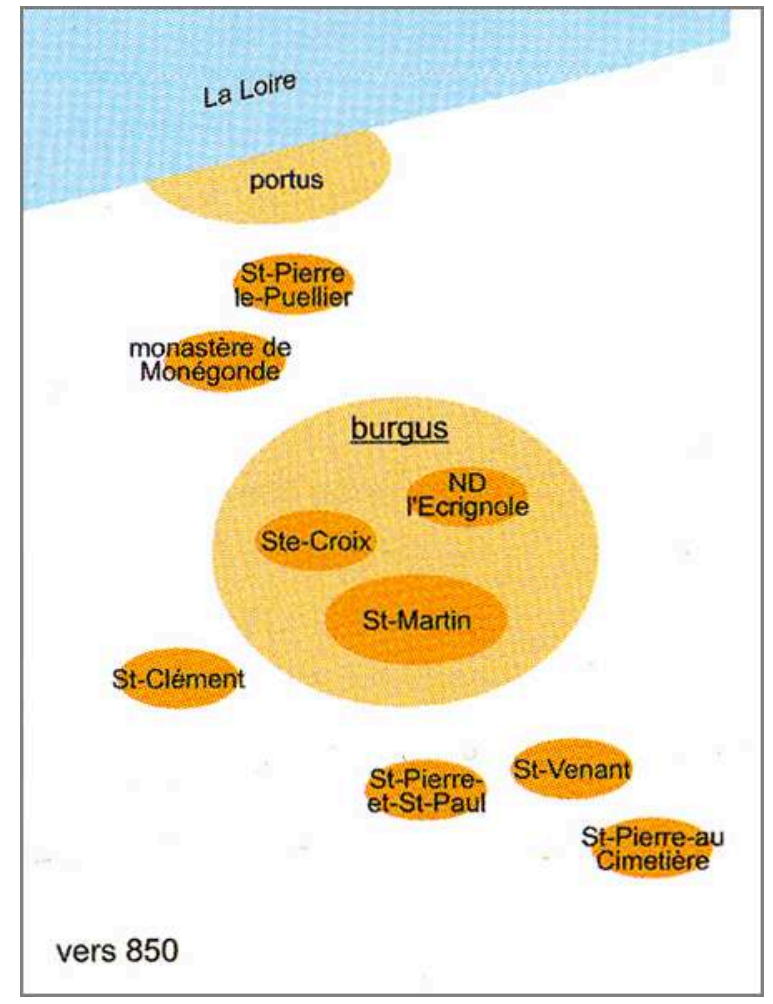

\section{Nonantola}

Cette connotation spatiale, tout en gardant à l'esprit qu'il s'agit d'une communauté canoniale, - qui, donc, ne peut pas être expressément assimilée à un ensemble monastique -, peut quand même fournir une importante clé d'interprétation pour d'autres situations, comme dans le cas de l'abbaye de Nonantola, près de Modène. 
d'un burgus a sero castri Nonantule au siècle suivant (1058) ${ }^{31}$. D'après les récentes propositions de restitution du site ${ }^{32}$ (fig. 5), au nord-ouest de l'enclos se serait développé à la même période le noyau originaire - ou un des plus anciens noyaux - du bourg monastique, qui aurait été inclus, vers le milieu du $\mathrm{XI}^{\mathrm{e}}$ siècle, dans l'enceinte construite par l'abbé Gothescalc, regroupant à la fois le monastère et l'habitat laïque qui l'entoure.

Fig. 5 - Nonantola, monastère Saint-Sylvestre. Hypothèse de restitution de l'habitat avant le milieu du XI ${ }^{\mathrm{e}}$ siècle (en haut) et entre le XI ${ }^{\mathrm{e}}$ et le XIII' siècle (en bas) ; d'après $\mathrm{S}$. GELICHI et M. LIBRENTI, "Nascita e fortuna di un grande monastero altomedievale. Nonantola e il suo territorio dalla fondazione al XIV secolo ", in F. DE RUBEIS et F. MARAZZI (dir.), Monasteri in Europa occidentale (secoli VIII-XI) : topografia e strutture, Rome, 2008, p. 255, fig. 5 et 6.
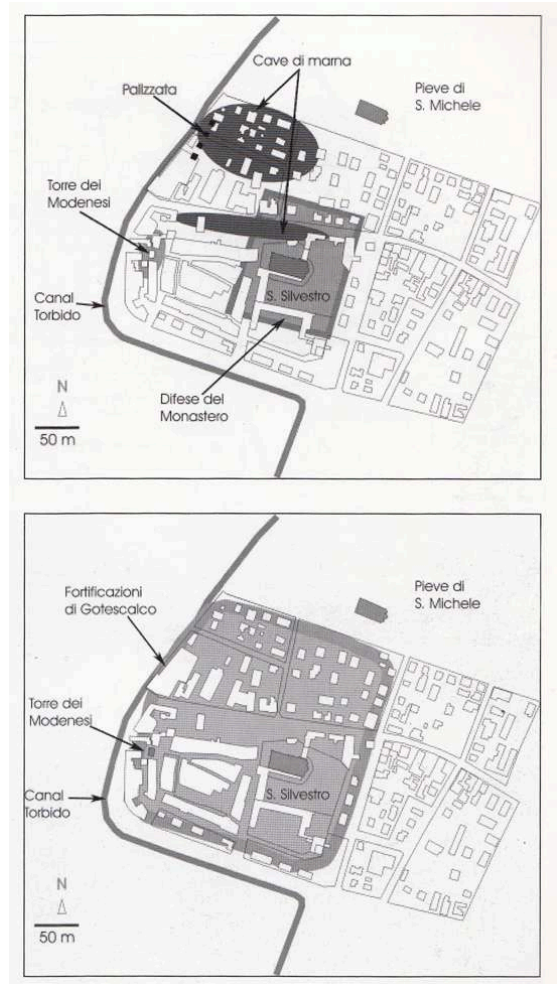

Vers le nord, à l'extérieur de cette enceinte, dans le dernier quart du IX ${ }^{\mathrm{e}}$ siècle, surgit l'église paroissiale de l'abbaye, Saint-Michel, qui a été récemment fouillée et dont la phase remontant au haut Moyen Âge est bien connue ${ }^{33}$.

On ne dispose pas de données pour localiser précisément, dans ce contexte, l'hôpital du monastère, pourtant bien documenté à partir des années vingt du XII siècle, quand on 
trouve les mentions de l'hospitale et de la firmaria, déjà citée en 898 : à cette date, elle apparaît dans un diplôme de l'empereur Lambert, qui donne des biens pro cedificanda et manutenendo infirmaria monasterii ${ }^{34}$. Au XIII ${ }^{\mathrm{e}}$ siècle, les deux institutions sont distinguées, bien que toujours strictement liées entre elles et agissant ensemble: en effet, un document datant de 1224 cite le moine Johannis, qualifié de prepositus firmarioe, et son confrère Adam, qui revêt la charge de prepositus hospicii eiusdem monasterii, passant un contrat de location de biens de l'abbaye ${ }^{35}$. Il n'est pas question, dans ces documents, de la position de ce complexe hospitalier. Un document plus tardif, datant de 1334, permet pourtant de placer l'ensemble destiné à l'accueil et aux soins des malades dans le burgus à l'orient du monastère (burgus de mane) ${ }^{36}$. À cette époque, au moins - mais peut-être s'agit-il de la même situation que l'on peut imaginer pour des moments précédents -, les structures de l'hôpital sont à l'extérieur du monastère, à l'est de celui-ci, dans un agglomérat que l'on ne connaît pas du tout du point de vue archéologique, mais qui est attesté directement depuis 1258 et, de façon moins évidente mais plausible, dès le $\mathrm{XI}^{\mathrm{e}}$ siècle, si la mention d'un burgus de sero impliquait la nécessité de le distinguer d'un burgus de mane.

Les sources écrites ne font pas état d'une église rattachée à l'ensemble hospitalier, tandis qu'un oraculum dédié à Saint-Ambroise est mentionné dans la vie de saint Anselme, rédigée au $\mathrm{XI}^{\mathrm{e}}$ siècle ${ }^{37}$. Le texte hagiographique relate que le saint l'institua, prope monasterium, à quatre milles de celui-ci, pour y accueillir les debiles et les femmes, qui ne pouvaient pas rentrer dans l'espace des moines. Cet ensemble d'assistance était donc pourvu d'un lieu de culte, aujourd'hui disparu, mais bien attesté dans la documentation, notamment depuis le début $\mathrm{du} \mathrm{XII}^{\mathrm{e}}$ siècle ${ }^{38}$ : il se trouvait au sud de l'abbaye (fig. 6), au lieu où s'élevaient le pont sur le fleuve Panaro et un important carrefour routier, où se croisaient la via Aemilia - dans le sens est-ouest - et la route reliant Nonantola aux Appenins et à la Toscane - dans le sens nord-sud ${ }^{39}$. 
Fig. 6 - Nonantola, localisation de l'oratorium Saint-Ambroise (dans le cercle) par rapport au monastère ; d'après $\mathrm{P}$. MUCCl et E. TROTA, " La strada medievale fra Nonantola e la Toscana ", in Viabilità antica e medievale nel territorio modenese e reggiano. Contributi di studio, Modène, 1983, p. 55 , fig. 3.

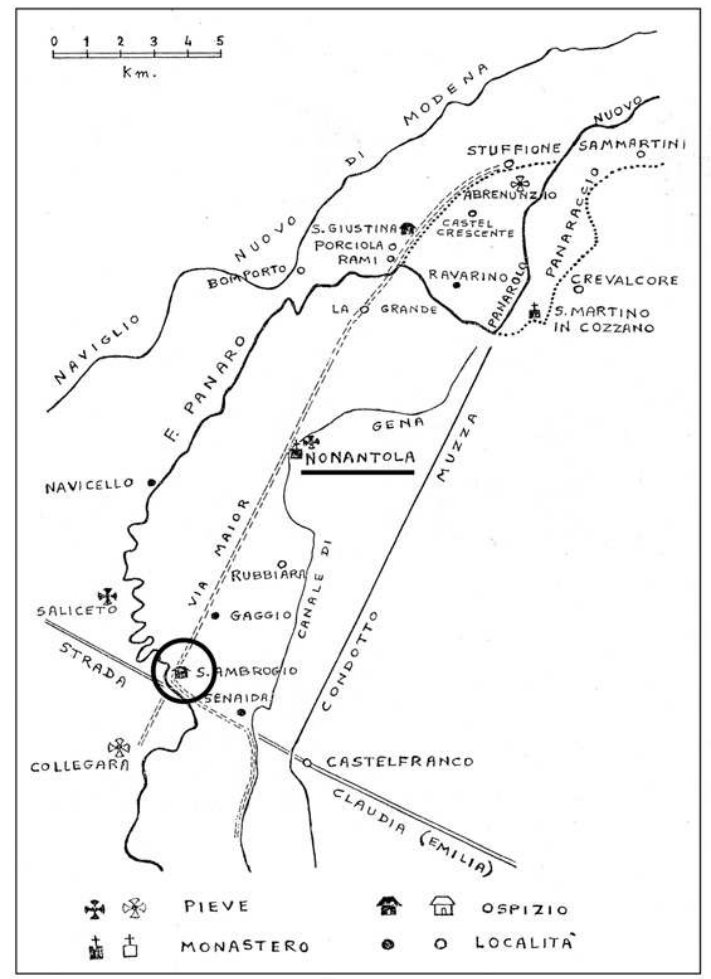

Cette mention présente plusieurs points d'intérêt, tout d'abord pour la précision de la distance de quatre milles, qui revient ailleurs dans des documents dès l'époque lombarde, qualifiant, par exemple, l'étendue de la première dotation foncière de Bobbio - in circuitu miliaria quattuor - autour du monastère ${ }^{40}$. Une étude récente de Florian Mazel a bien mis en évidence la valeur même symbolique et assez standardisée de cette distance - allant de trois à sept milles autour de l'abbaye -, qui marque un espace particulier - parfois même au niveau juridique - entourant le pôle monastique : dans certains cas, comme à Saint-Gilles, le secteur délimité correspond, dans une période plus avancée du Moyen Âge, à l'aire de paix du monastère ${ }^{41}$.

L'oraculum Saint-Ambroise de Nonantola se trouve donc très vraisemblablement dans une zone de "frontière ", en lisière de l'espace monastique, avec peut-être du personnel attaché (servientes) au service des hôtes, dans un ensemble architectural qu'on ne peut pas assimiler tout court aux xenodochia de l'abbaye, plus éloignés et documentés dans d'autres régions de l'Italie du Nord ${ }^{42}$. Ce site semble, au contraire, complémentaire de l'abbaye (et de son hôpital), notamment du point de vue fonctionnel, puisqu'il fournit l'assistance spirituelle et matérielle à des catégories de personnes, qui, tout en voulant se rapprocher le plus possible du claustrum, ne peuvent pas le faire : les femmes et les debiles, un terme, qui, à son tour, semble assez flou, mais qui, ici, pourrait indiquer les malades au sens propre du mot. Grâce à cette fonction spécifique, l'oraculum semble être, par conséquent, strictement lié à l'abbaye, situé aux abords de l'espace directement contrôlé par la communauté, dont il marque, d'une certaine façon, la limite, en s'élevant auprès de l'un de ses accès principaux. 


\section{Novalaise}

Ce lien entre les femmes et une église desservant un espace d'accueil près d'un monastère, qui est en même temps un marqueur de ses limites spatiales, n'est d'ailleurs pas isolé. Le cas de Novalaise (fig. 7), fondée en 726 par le patrice mérovingien Abbon, le long de la route du col du Montcenis ${ }^{43}$, montre des points de contact fort intéressant à ce propos.

Fig. 7 - Novalaise, monastère Saint-Pierre et Saint-André. Localisation de la chapelle Sainte-Marie par rapport au centre abbatial ; d'après G. CANTINO WATAGHIN, « L'abbazia di Novalesa alla luce delle indagini archeologiche : verifiche e problemi ", in Nel millenario di S. Michele della Chiusa. Dal Piemonte all'Europa : esperienze monastiche nella società medievale, Turin, 1988, p. 579, fig. 1.

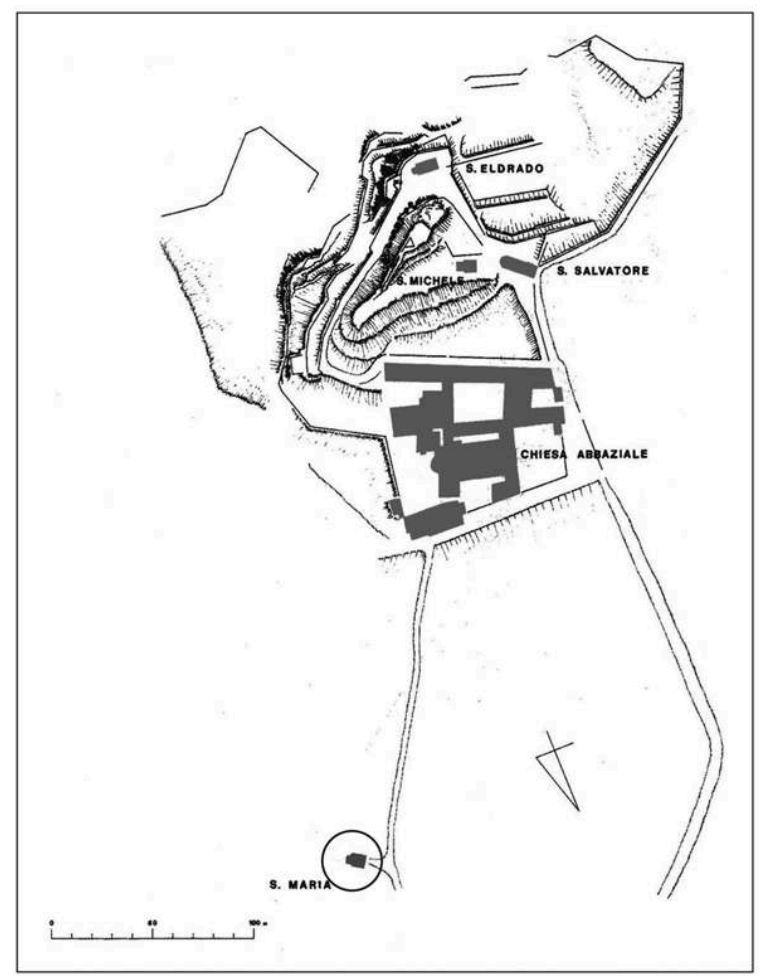

31 Au milieu du $\mathrm{XI}^{\mathrm{e}}$ siècle, le rédacteur anonyme de la chronique de l'abbaye relate la présence dans le monastère du haut Moyen Âge d'un bâtiment (domus), dans lequel étaient abritées «toutes les femmes qui se rendaient là-bas pour adorer Dieu " ${ }^{44}$. Cette domus, d'après l'auteur de l'ouvrage, s'élevait tout près de la chapelle Sainte-Marie (fig. 8), qui subsiste encore aujourd'hui en élévation, et qui montre deux phases principales de construction - précédées par un édifice, peut-être déjà cultuel, plus ancien -, remontant au viII ${ }^{\mathrm{e}}$ et au $\mathrm{X}^{\mathrm{e}}$ siècle ${ }^{45}$. 
Fig. 8 - Novalaise, monastère Saint-Pierre et Saint-André. La chapelle Sainte-Marie (cl. E. Destefanis).

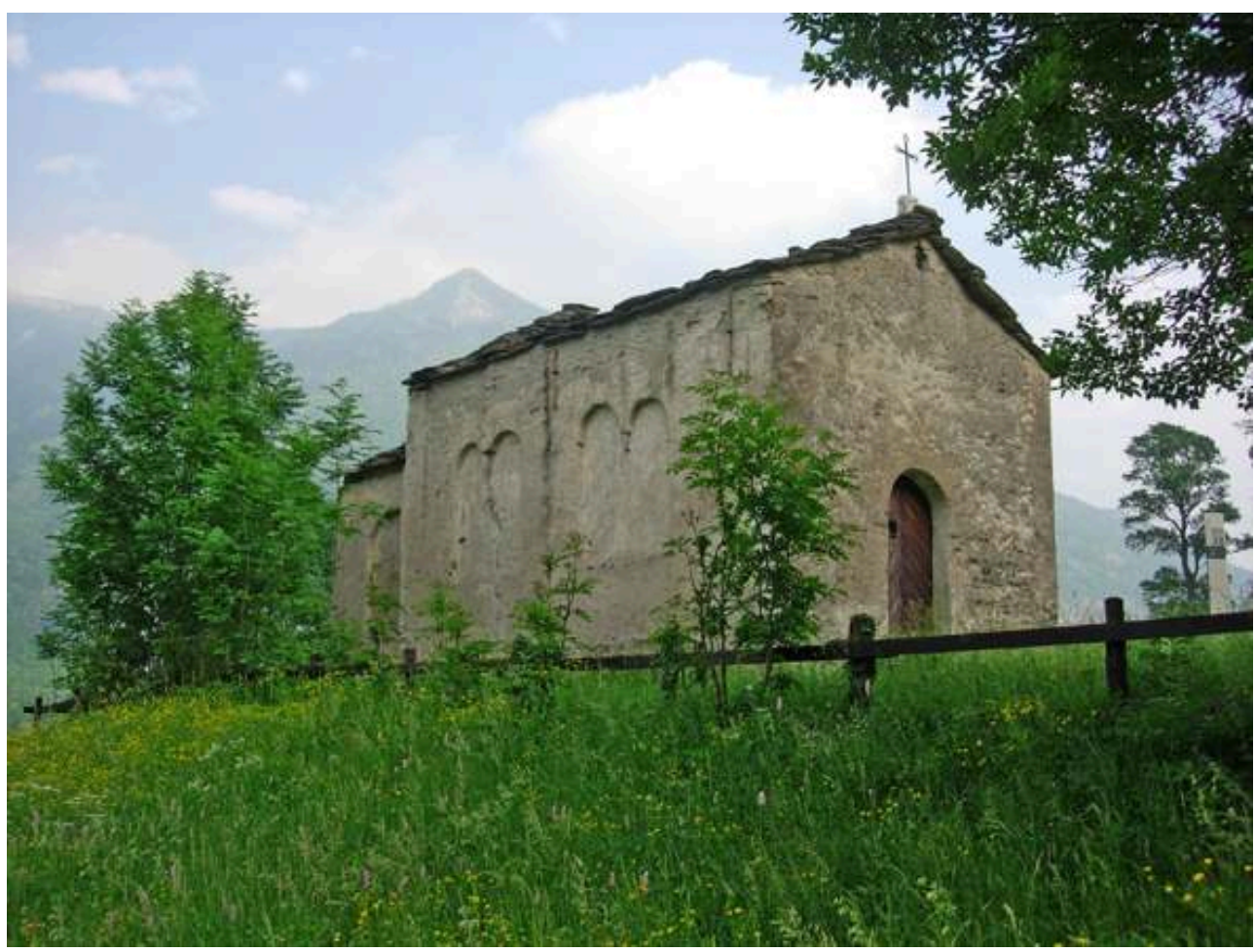

Parmi les quatre chapelles qui entourent l'abbatiale, elle est la plus éloignée par rapport à celle-ci, s'élevant à environ deux cents mètres de l'église principale. Ce petit lieu de culte est très vraisemblablement à situer en rapport avec l'enceinte du monastère, que l'on ne connaît pas archéologiquement, mais dont il reste probablement une trace dans l'irrégularité du terrain et dans la disposition de la végétation toute proche de la chapelle ${ }^{46}$.

D'ici, commençait, selon la Chronique, le chemin qui menait à l'abbaye. Le lieu était marqué par une croix à reliques, qui mettait en évidence cette limite infranchissable pour les femmes, sous peine de terribles punitions physiques ou même de la mort ${ }^{47}$. La présence de la croix semble souligner ultérieurement cette fonction « liminale » de la chapelle, capable d'assurer le soulagement spirituel aux femmes, mais en même temps à leur rappeler la barrière (surnaturelle avant tout) face à laquelle elles se trouvent : un entre-deux, entre le monde profane et le monde sacré du claustrum, auquel de strictes interdictions règlent l'accès et dont l'ordre ne doit pas être perturbé, notamment à cause des femmes.

Le problème de l'accès des femmes à l'église abbatiale dans les monastères et, plus en général, aux reliques, a été bien étudié par Julia Smith ${ }^{48}$ : elle retrouve les origines de cette interdiction dans une conception du monachisme lérinien/méditerranéen, bien illustrée par l'épisode de saint Roman, relaté par Grégoire de Tours, qui décide de se faire enterrer loin de sa propre communauté, dans le Jura. Comme on l'apprend de la Vita patrum iurensium, il est enseveli dans une chapelle funéraire, à l'extérieur du monastère de sa sœur, à La Balme ${ }^{49}$, pour éviter aux femmes venues en pèlerinage sur son tombeau d'entrer en contact avec les frères.

35 À l'époque carolingienne, cette conception aurait été reprise, d'une façon inégale, afin de « préserver l'intégrité du monastère comme espace protégé de la contamination des 
influences du siècle ${ }^{50}$. Différentes stratégies furent par conséquent mises en place pour permettre aux femmes de se rapprocher des objets de dévotion - ce qui peut aussi impliquer le déplacement temporaire des reliques - et de participer à la prière et à la vie sacramentelle, tout en restant à l'extérieur du claustrum qui leur était interdit.

\section{Bobbio}

À Bobbio, le texte anonyme des Miracula sancti Columbani, rédigé vers 970, relate la présence d'une église dédiée à la Vierge, dont l'édification est attribuée directement à Colomban, bien que sa reconstruction en pierre (plausiblement sa construction) remonte à l'abbé Agilulphe, à la fin du $\mathrm{IX}^{\mathrm{e}}$ siècle ${ }^{51}$. Cette église a été identifiée avec l'abbatiale - dédiée toutefois à saint Pierre - par Michele Tosi ${ }^{52}$, mais l'analyse globale de la documentation écrite de l'abbaye disponible pour le haut Moyen Âge ouvre d'autres pistes d'interprétation, notamment en suggérant de reconnaitre dans cette ecclesia mariale, dont les Miracula n'indiquent pas l'emplacement au sein du site monastique, une église secondaire rattachée au monastère, ayant des fonctions spécifiques et complémentaires par rapport à l'abbatiale. Celles-ci sont probablement précisées par un document bien plus tardif, relatant les actes du procès de Cremone de 1207 , quand l'abbaye fit la dernière tentative de garder sa propre autonomie (tout d'abord patrimoniale) de l'évêché, institué à Bobbio en 1014 et jouissant, depuis cette date, d'un rôle de plus en plus proéminent par rapport à la communauté monastique ${ }^{53}$.

À l'occasion de ce procès, qui marque l'assujettissement définitif de l'abbaye à l'évêque, les témoins des deux parties soutiennent les raisons de deux institutions en opposition : parmi ceux de l'abbaye, le prêtre Petrocus se concentre sur l'église des chanoines qui desservent à cette époque la cathédrale. Il atteste que cette ecclesia canonicorum, qui est aussi appelée ecclesia nova ${ }^{54}$, avait été construite auparavant par le monastère, à l'usage des femmes qui ne pouvaient pas rentrer dans l'espace monastique, sous peine comme on l'a vu à Novalaise - de terribles punitions. Dans cette église, appelée aussi anciennement plebes (plebs) monasterii, elles pouvaient recevoir le baptême et les sacrements ${ }^{55}$, ce qui suggère d'associer cet édifice à un lieu d'accueil (au moins spirituel) pour les femmes ainsi que de cura animarum, sous le strict contrôle du monastère.

Au-delà de l'identification que l'on peut suggérer de l'ecclesia Sainte-Marie des Miracula avec l'ecclesia nova - ainsi nommée en tant que construction de la fin du $\mathrm{IX}^{\mathrm{e}}$ siècle ? - / plebs monasterii / ecclesia canonicorum ${ }^{56}$, l'emplacement précis de l'église au service des femmes demeure inconnu, même s'il est possible de songer au quartier épiscopal (fig. 9) - la cathédrale est d'ailleurs aussi dédiée à sainte Marie -, à moins de cent cinquante mètres du monastère Saint-Colomban. 
Fig. 9 - Bobbio, vue générale de l'habitat : au centre de l'image, l'abbaye Saint-Colomban ; au premier plan, l'ensemble épiscopal (cl. D. Garilli).

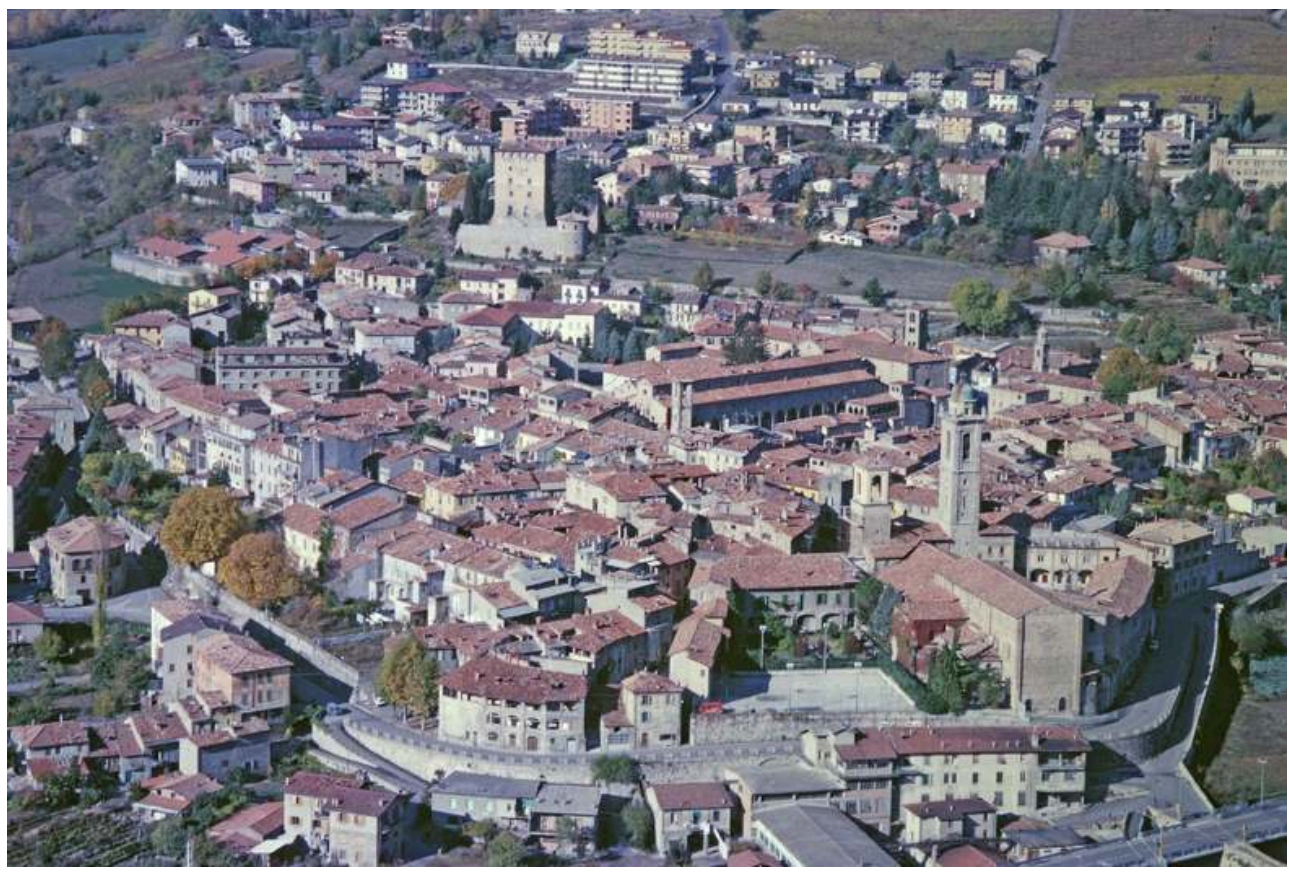

Ce lieu, d'ailleurs, se trouve dans une position particulièrement favorable au niveau du réseau de communication du site, tout près du pont, qui, permettant de traverser le fleuve Trebbia, donne accès à l'une des routes principales de toute la région, qui menait à la Ligurie orientale - et donc à la Méditerranée - et à l'Italie centrale ${ }^{57}$.

Pendant le $\mathrm{xl}^{\mathrm{e}}$ siècle, l'ecclesia nova est mentionnée dans plusieurs documents, où apparaît aussi l'ecclesia infirmorum ${ }^{58}$, dont l'identification demeure également incertaine : elle a été associée à l'église de l'hospitale ${ }^{59}$, tandis que, s'il ne s'agit pas de l'église pour les moines malades, une hypothèse récente propose de la reconnaître dans l'église Saint-Lazare, citée dans la documentation du bas Moyen Âge ${ }^{60}$. À Bobbio, l'assistance charitable est en tout cas bien documentée depuis l'époque carolingienne, comme en témoigne le breve memorationis de l'abbé Wala (835-836), qui mentionne les charges du custos infirmorum, des hospitaliarii religiosorum et de l'hospitaliarius pauperum; ce dernier reçoit du portier la dîme de toutes les revenues du monastère pour le soutien économique des pauperes qu'il accueille ${ }^{61}$. L'hospitale - ici dans le sens d'hospitale pauperum - est mentionné plusieurs fois, y compris dans les Miracula sancti Columbani, où certains des pauperculi sont assistés pendant des années ${ }^{62}$. Dans ce texte, pourtant, il n'y a pas mention d'un lieu de culte rattaché à l'institution charitable du monastère ${ }^{63}$.

\section{Farfa}

41 La création d'une église - très souvent avec une dédicace mariale - à la limite du monastère semble donc bien répondre à l'exigence d'accueillir les femmes et leur offrir une assistance à la fois matérielle et spirituelle. C'est d'ailleurs une situation bien connue, même au-delà de l'Italie si l'on songe par exemple à la situation de Lobbes, où une église mariale, ouverte au populus et notamment aux femmes, fût bâtie sur la 
colline dominant le monastère ${ }^{64}$. Le cas de Farfa (fig. 10), dans un contexte encore plus complexe, est également intéressant à ce propos.

Fig. 10 - Farfa, localisation du monastère Sainte-Marie dans l'Italie centrale d'après C. MCCLENDON, The Imperial Abbey of Farfa. Architectural Currents of the Early Middle Ages, New Haven/Londres, 1987, p. XIV, fig. 1.

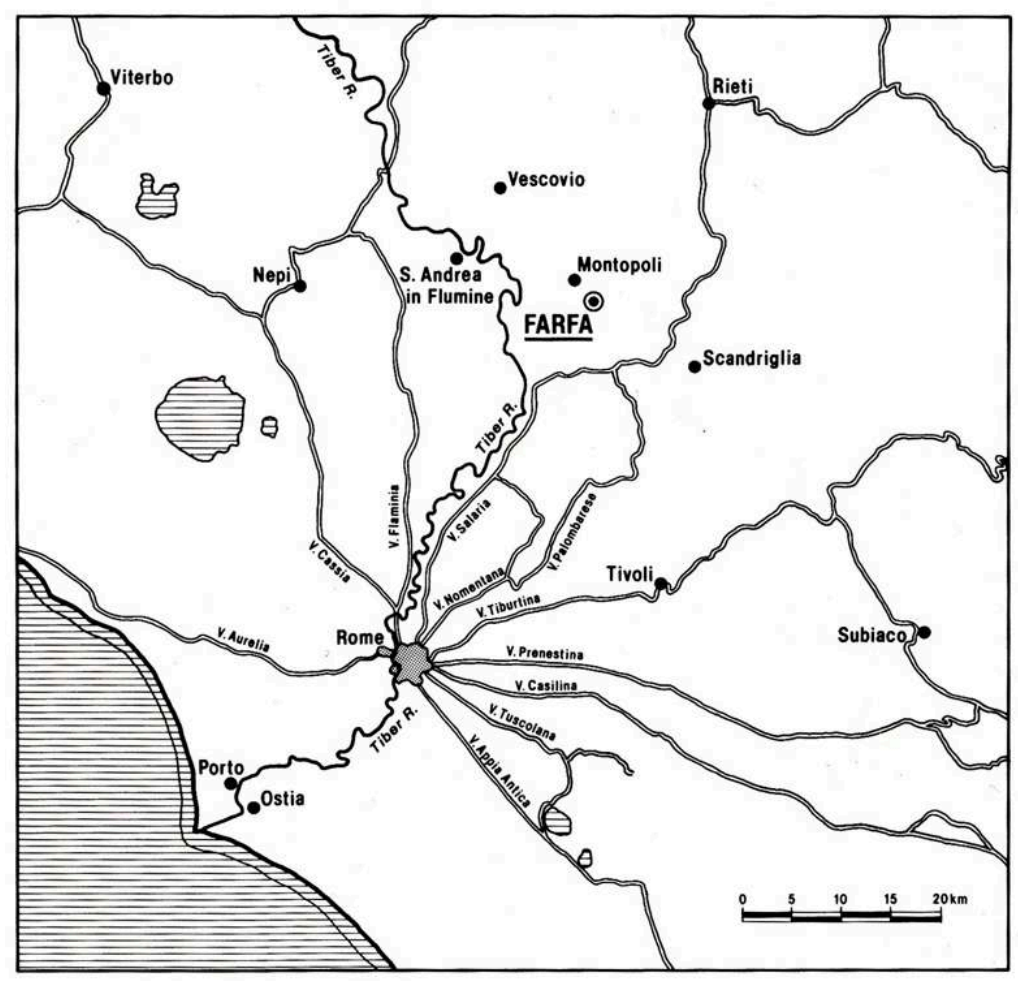

D'après le Chronicon farfense, rédigé par Grégoire de Catino pendant les deux premières décennies du XII ${ }^{e}$ siècle, l'abbaye aurait connu une première fondation par le moine syrien Laurent au $\mathrm{Vl}^{\mathrm{e}}$ siècle, et une seconde, à la suite des destructions lombardes, au début du VIII ${ }^{\mathrm{e}}$ siècle, par Thomas de Maurienne, qui en fût aussi le premier abbé ${ }^{65}$. Les sources du haut Moyen Âge décrivent l'abbaye Sainte-Marie comme un ensemble assez complexe. En particulier, le texte connu comme Destructio Farfensis, rédigé au début du $\mathrm{xl}^{\mathrm{e}}$ siècle par l'abbé Hugues et relatant l'état du monastère avant l'attaque sarrasinne de 898, mentionne l'abbatiale et cinq autres églises, dont deux sont au service des moines malades, une autre, dédiée à saint Pierre, est l'église des chanoines (in usu canonicorum), une quatrième, in palatio regali constituta, est affectée aux empereurs quand ils viennent visiter l'abbaye, tandis que la dernière est une église mariale, située extra muros, dite parva quidem sed mirifice constructa, ubi mulieres conveniebant orationis causa et visitationis ${ }^{66}$.

L'abbé explique également la raison pour laquelle cette chapelle a été construite à l'usage des femmes : en effet, ut senum refert relatio, antiquitus nulla mulierum intra muros illius ingrediebatur monasterii. Sans doute le texte fait allusion - en évoquant des pratiques dont on souligne l'ancienneté et par conséquent l'autorité - aux dispositions qu'on trouve à l'époque lombarde, quand, en 749 , le duc de Spolète, Lupo, établit que les femmes n'ont pas licence d'aller prier au monastère en traversant librement son territoire, mais qu'elles doivent suivre un parcours (ou des parcours) fixé, indiqué de façon ponctuelle dans le document ${ }^{67}$. 
Les lieux mentionnés comme permis aux femmes se trouvent surtout à l'ouest du monastère, dans une vaste zone que la cartographie historique de l'époque moderne montre encore comme située en lisière du territoire abbatial (fig. 11 et 12) ${ }^{68}$.

Fig. 11 - Farfa. Le monastère Sainte-Marie au sein de son territoire et du réseau routier : en bas, à gauche, la Strada Romana qui vient de Rome ; en haut, à gauche, la route qui mène vers l'Ombrie et le cœur du duché lombard de Spolète - à travers le Ponte Granica sur le Farfa ; au centre de l'image et à droite, la route qui conduit à la via Salaria romaine. Archive Abbatial de Farfa, Racc. Cart., xVIIeXVIII e siècle ; d'après T. LEGGIO et R. LORENZETTI, Le carte di Farfa. Le carte topografiche del territorio di Farfa (secc. XVIII-XIX), Farfa, 1998, p. 68.

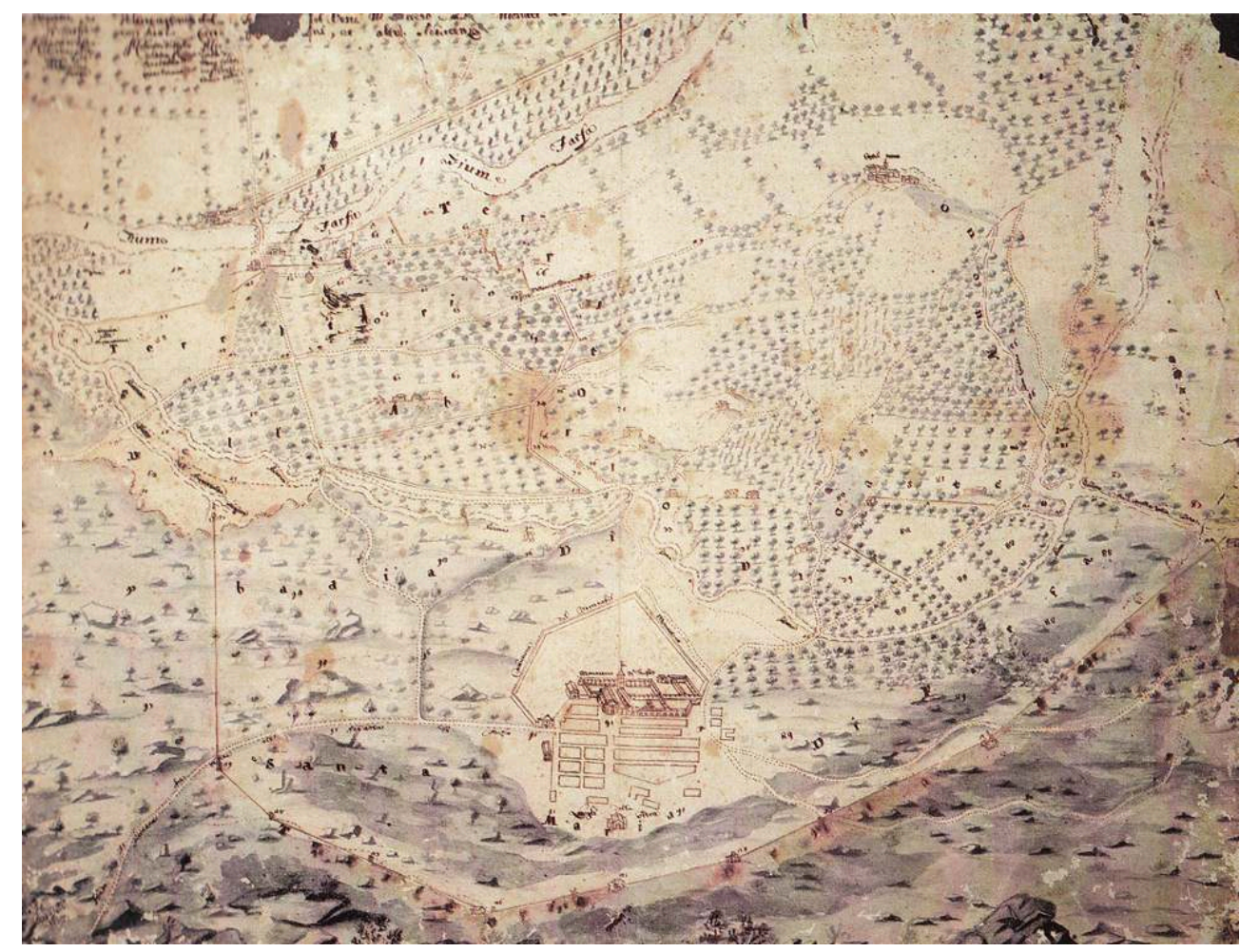


Fig. 12 - Farfa, le territoire abbatial (en rose) et ses limites, avec l'indication des termini. Archive d'État de Rome, PD, I, cart. 27, fol. 36, dessin de Domenico Sandi, 15 février 1790 ; d'après T. LEGGIO et R. LORENZETTI, Le carte di Farfa. Le carte topografiche del territorio di Farfa (secc. XVIII-XIX), Farfa, 1998, p. 71.

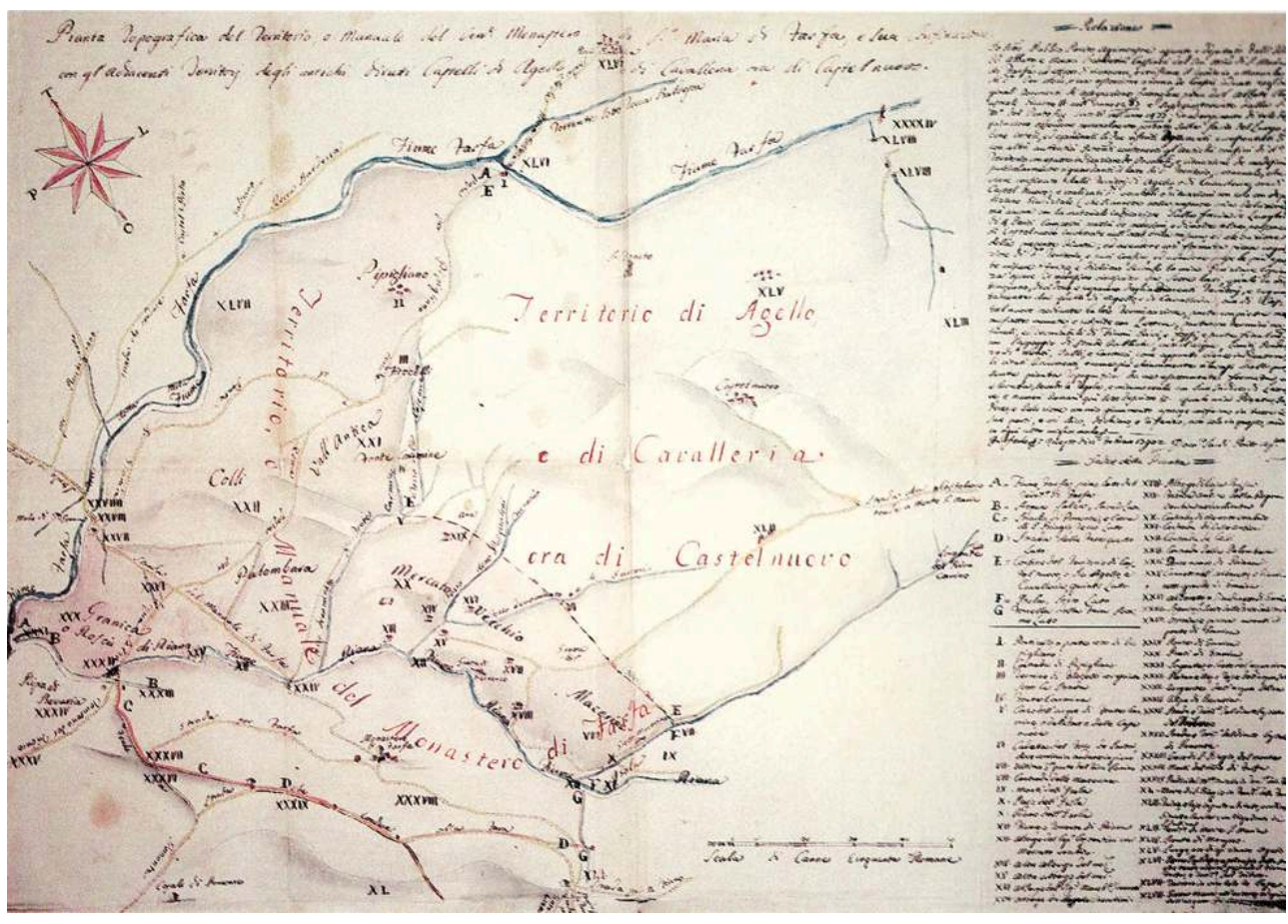

On ne sait rien de l'emplacement de l'église Sainte-Marie, mais, si l'on en croit la Destructio, elle aurait dû s'élever aux abords de l'espace parcouru par les femmes, qui n'avaient aucun droit d'accès aux alentours immédiats de l'abbaye ${ }^{69}$ : à l'occasion de la visite de quelque reine où d'autres femmes (sans doute de rang), l'abbé ou des moines pouvaient sortir du monastère et aller les rencontrer, ut cum eis de spiritualibus agerent que oportent ${ }^{70}$. Il est ici question d'une assistance avant tout spirituelle, mais il semble logique de penser aussi à un accueil attentif aux exigences matérielles pour ce genre de visiteurs.

Les structures d'accueil au sein de l'abbaye sont mentionnées par les documents dès l'époque lombarde - un testament de 768 parle de senodochias pour le peregrini et les minus potentes ${ }^{71}-$, mais la première mention explicite d'une domus hospitum date de 1119, époque où l'on octroie à cette institution le casalem iuxta eundem hospitalem ainsi que d'autres biens, dont les dîmes servant au soutien de l'hôpital ${ }^{72}$. La mention du casale jouxtant le lieu d'accueil laisse supposer une position au moins aux marges de l'enclos monastique, si non dans sa proximité, immédiatement à l'extérieur. On ne connaît la localisation de l'hôpital qu'à une époque très tardive, lorsqu'au dernier quart $\mathrm{du} \mathrm{XvI}{ }^{\mathrm{e}}$ siècle, cette structure se trouvait dans le coin nord-ouest de l'abbaye, près de la douane pour les marchandises, bâtie à cette époque et que situe ponctuellement grâce à une gravure du XviI ${ }^{\mathrm{e}}$ siècle ${ }^{73}$.

D'après Schuster, à l'hôpital - de toute façon, comme on l'a dit, situé probablement en lisière du monastère - aurait été associée la chapelle Saint-Pierre ${ }^{74}$, affectée aux chanoines qui auraient également eu la charge de l'assistance. L'hypothèse de la proximité de l'église à la structure d'accueil n'est sans doute pas à rejeter tout court, en considérant les dispositions du concile d'Aix-la-Chapelle évoquées ci-dessous, mais aucun indice ne subsiste pour sa localisation, à l'exception du fait qu'elle était 
probablement située à l'extérieur de l'enclos, tout près de celui-ci. Cette position est suggérée par des documents du $\mathrm{XI}^{\mathrm{e}}$ siècle rédigés iuxta ipsum suprascriptum monasterium ante ecclesiam sancti Petri ${ }^{75}$, dont l'un voit une femme comme acteur principal; un élément qui offre l'avantage de placer l'église dans un espace, qui, tout en étant infra monasterium/in monasterio, n'est pas inclus dans l'enceinte. Ce n'est pas le seul cas de chapelles s'élevant in monasterio, dans lesquelles ou près desquelles sont rédigés des actes voyants impliqués des femmes et que l'on peut sans doute localiser aux marges du claustrum ou à l'extérieur de celui-ci, en marge de l'espace monastique ${ }^{76}$.

Les fouilles sur le site, menées à plusieurs reprises au cours du $\mathrm{xx}^{\mathrm{e}}$ siècle et, notamment, pendant les années 1980 et 1990 par la British School at Rome, ont mis en évidence une église avec un chevet occidenté, pourvue d'un transept et d'une crypte annulaire (fig. 13) ${ }^{77}$; le chevet lui-même est enveloppé par un déambulatoire, qui était raccordé vers l'ouest à un espace ouvert ; à l'est, un chœur carré flanqué par deux tours - dont l'une subsiste en élévation - est attribué selon les auteurs à l'époque carolingienne ou à la période proto-romane.

Fig. 13 - Farfa, reconstitution de l'ensemble monastique au milieu du Ix ${ }^{\mathrm{e}}$ siècle (en haut) et au milieu du XI ${ }^{\mathrm{e}}$ siècle ; d'après C. MCCLENDON, The Imperial Abbey of Farfa. Architectural Currents of the Early Middle Ages, New Haven/Londres, 1987, fig. 15.

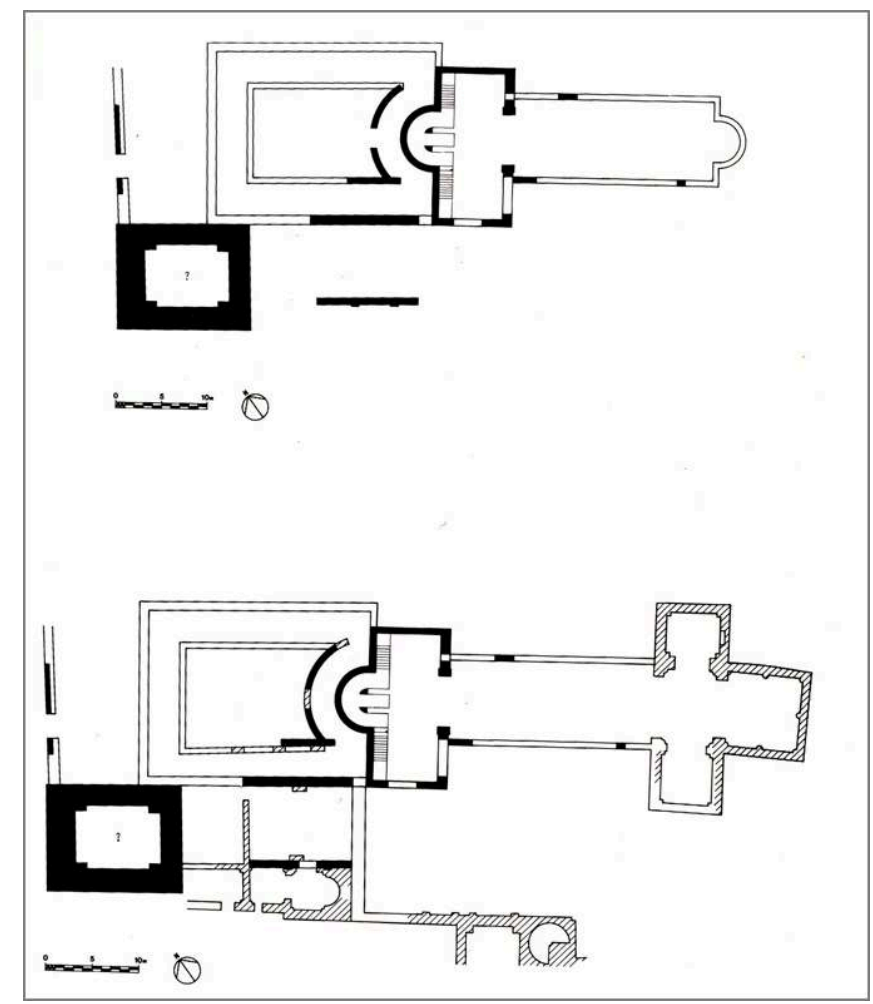

Après la découverte du secteur occidental, les interprétations ainsi que les propositions de phasage et de chronologie se sont multipliées ${ }^{78}$. La zone au sud et à l'ouest de l'église a également restitué une série de structures, dont les traces d'un porche (plusieurs fois agrandi), qui, entre le $\mathrm{VIII}^{\mathrm{e}}$ et le $\mathrm{IX}^{\mathrm{e}}$ siècle, abritait un accès, le seul connu pour cette époque à l'abbaye. Tout le secteur compris entre ce porche et le chevet de l'église, où McClendon place un atrium avec des galeries (fig. 13), a été occupé par des sépultures privilégiées, comme le suggère la présence d'un sarcophage romain de remploi, retrouvé dans le déambulatoire. Plus au sud, un bâtiment dont subsiste le mur 
gouttereau nord, décoré avec des peintures murales très élaborées, a été identifié comme appartenant à une chapelle ; celle-ci aurait ensuite été remplacée, après une phase d'incendie et de destruction, associée à l'attaque des Sarrazins de 898, par un second édifice de culte, actuellement visible et retrouvé en fouille.

Cette église, en considération de sa position aux abords du claustrum, a été reconnue comme celle destinée à l'empereur, dont le palatium a été attribué à ce secteur de l'abbaye ; la tour massive s'élevant immédiatement à l'ouest de la chapelle (fig. 14), encore préservée aujourd'hui, aurait fait partie de cet ensemble ${ }^{79}$.

Fig. 14 - Farfa, monastère Sainte-Marie. La tour auprès de l'accès à l'abbaye depuis l'ouest (cl. E. Destefanis).

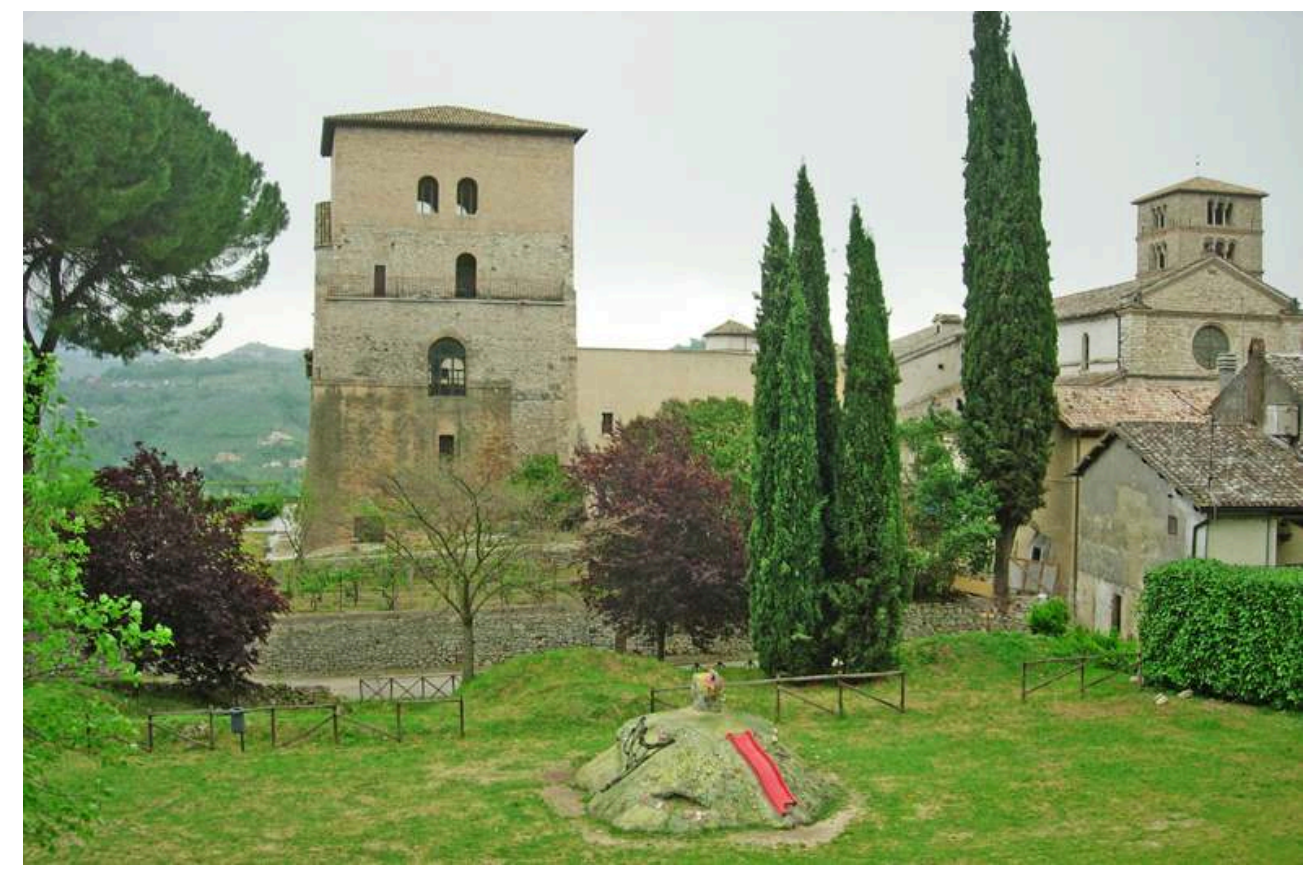

51 Quoi qu'il en soit, la position de la chapelle, proche d'un accès au monastère et d'un axe routier important menant depuis Rome et la via Salaria vers l'Ombrie, pourrait confirmer une vocation d'édifice cultuel lié à un pôle d'accueil ${ }^{80}$.

\section{San Vincenzo al Volturno}

52 Une situation également complexe, dans le cadre des chapelles-satellite pouvant avoir fonction d'accueil, a été mise en évidence par les fouilles menées à San Vincenzo al Volturno, qui ont impliqué jusqu'à présent seulement une partie de la vaste abbaye (fig. 15), fondée pendant les premières années du viII ${ }^{\mathrm{e}}$ siècle et pourvue au haut Moyen Âge de plusieurs lieux de culte mentionnés par les sources écrites ${ }^{81}$. 
Fig. 15 - San Vincenzo al Volturno, plan du monastère au haut Moyen Âge (à gauche) et du monastère de l'époque romane, avec l'hypothétique emprise du bourg ; d'après R. HODGES, S. LEPPARD et J. MITCHELL (dir.), San Vincenzo Maggiore and its Workshops, Rome/Londres, 201 1, p. 7, fig. 1.4.

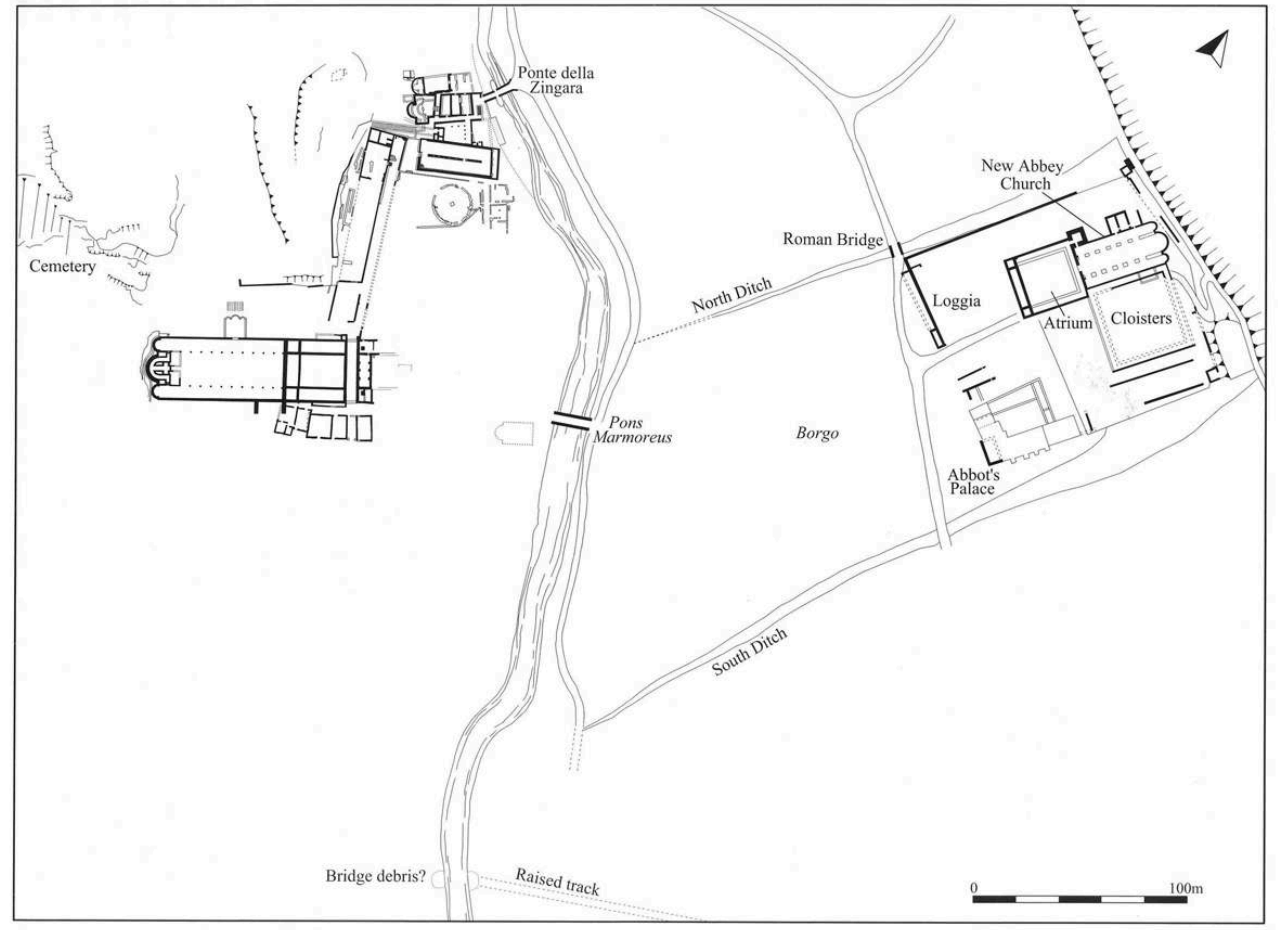

Le seul accès aujourd'hui connu au site se trouvait au nord, au bout d'un appontement en bois, qui vient d'être découvert. Ici, au vIII siècle, s'élevaient deux églises (fig. 16) : celle plus au sud ("South Church»), déjà identifiée avec la première abbatiale ${ }^{82}$, semble par contre à identifier, d'après des études récentes, avec l'ecclesia Sancte Marie iuxta flumen que Minor vocabatur, mentionnée par le Chronicon vulturnense (vers 1130), qui en attribue la construction à l'abbé Paul (783-792) ${ }^{83}$; la seconde, dont l'identification avec les nombreuses églises secondaires mentionnées dans le Chronicon demeure incertaine, s'élève immédiatement au nord de l'autre ${ }^{84}$. 
Fig. 16 - San Vincenzo al Volturno, plan des églises auprès de l'accès au nord de l'ensemble au VIII' siècle; d'après R. HODGES, S. LEPPARD et J. MITCHELL (dir.), San Vincenzo Maggiore and its Workshops, Rome/Londres, 2011, p. 7, fig. 1.3.

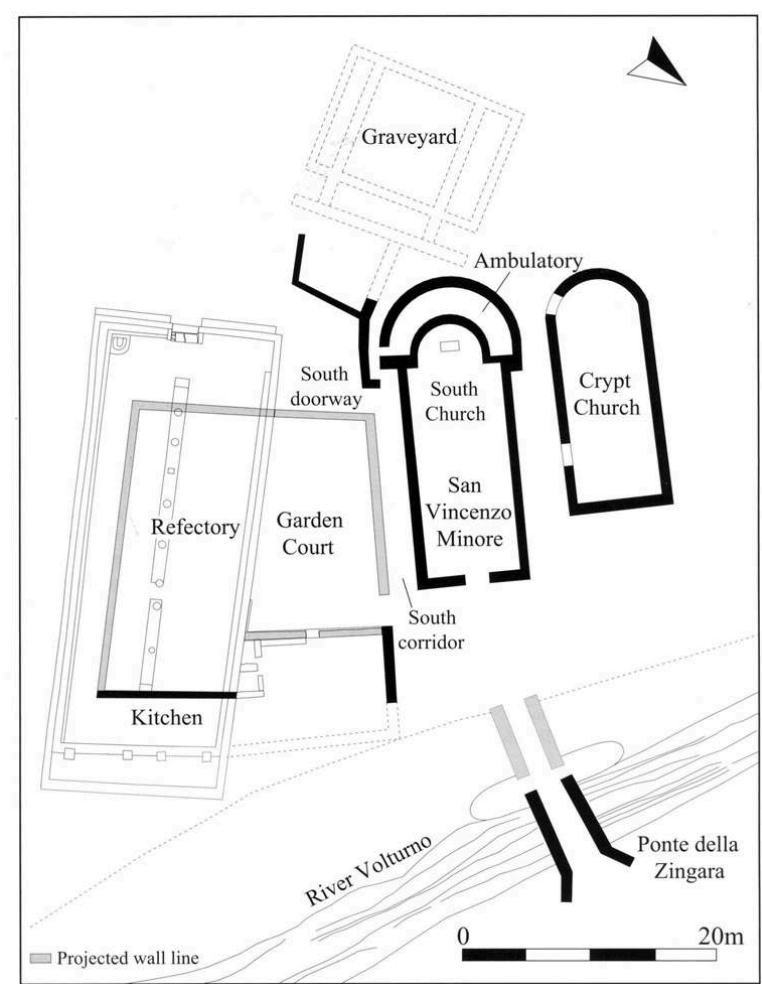

54 La «South Church» représente un important pôle de dévotion, comme le démontrent la présence d'un autel richement décoré au milieu de son abside ainsi qu'un déambulatoire derrière celle-ci, qui permettait aux fidèles de voir l'intérieur de l'église à travers une fenêtre perchée dans l'axe de l'abside même. Pendant les premières années du IX $\mathrm{x}^{\mathrm{e}}$ siècle, une importante transformation est attestée (fig. 17) : son chevet est séparé du reste du bâtiment par un couloir, au-delà duquel, vers l'est, s'ouvrent trois pièces ayant une fonction de service, dont l'une servant probablement d'étable; un porche précède vers l'est la façade, tandis que des traces d'un escalier dans le même secteur indiquent la présence d'un étage supérieur. 
Fig. 17 - San Vincenzo al Volturno. À gauche : plan de la « South Church » au début du IX siècle [d'après P. DELOGU, R. HIDGES et J. MITCHELL, San Vincenzo al Volturno. La nascita di una città monastica, Rome, 1996, p. 18, fig. 9] ; à droite : plan de l'ensemble au nord de l'abbaye, pendant le deuxième quart du IX siècle [d'après F. DE RUBEIS et F. MARAZZI (dir.), Monasteri in Europa occidentale (secoli VIII$X I)$ : topografia e strutture, Rome, 2008, p. 359, fig. 13b].
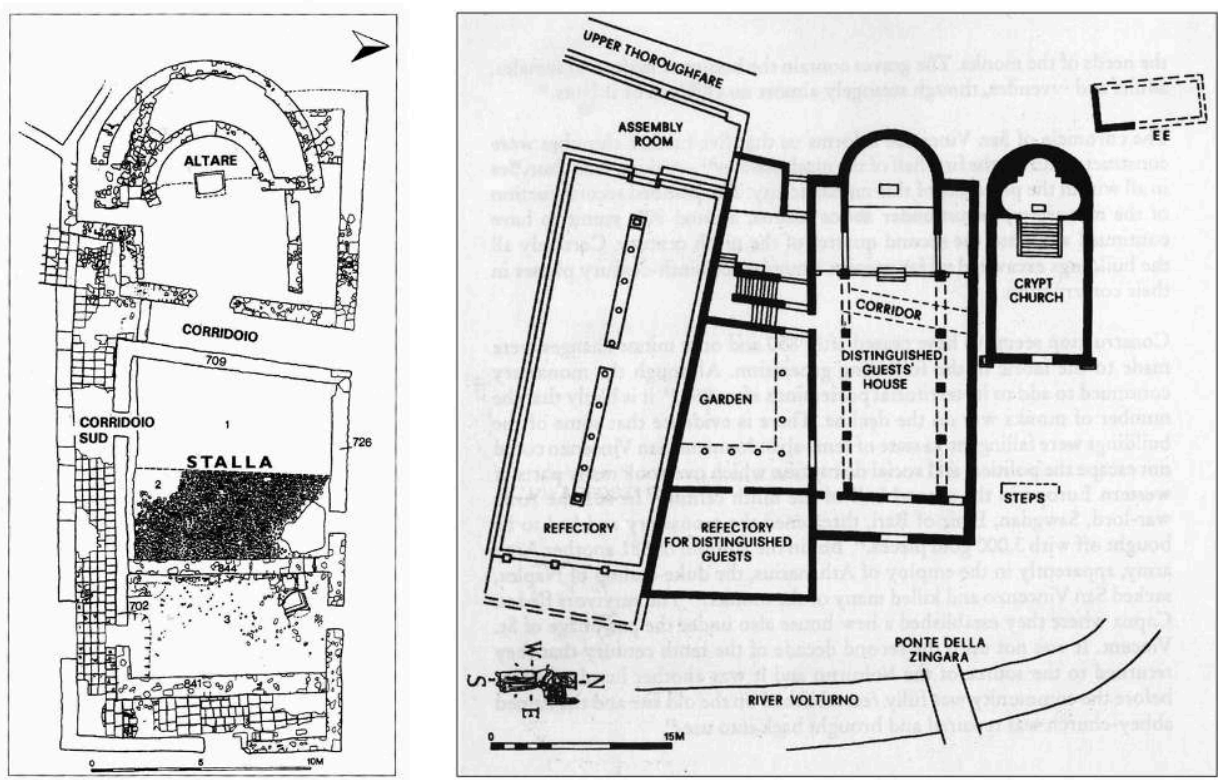

L'édifice est flanqué au sud par un long couloir, qui le sépare d'un jardin richement orné et d'une pièce rectangulaire bordant la rivière, également décorée par des fresques ${ }^{85}$.

Les fouilleurs anglais ont mis en relation le remaniement de l'église méridionale avec la création, tout près de l'un des accès au site, d'un ensemble destiné à l'accueil des hôtes de marque et notamment des patrons de l'abbaye - sans doute le duc de Bénévent. Pouvant séjourner à l'étage de l'ancienne église - recouvert d'enduits peints retrouvés en fouille - et laisser leurs montures au rez-de-chaussée, ils y auraient trouvé l'équivalent de leur demeure, en pouvant jouir d'un agréable jardin ainsi que d'un réfectoire réservé aux hôtes.

Tout en reconnaissant la suggestion de cette reconstruction ${ }^{86}$, sur laquelle pourtant Federico Marazzi a tout récemment exprimé des réserves ${ }^{87}$, le problème du rapport de ce nouvel ensemble à l'usage des laïques et des lieux de culte présents dans ce secteur reste ouvert, non seulement pour ce qui concerne la destinée de la partie absidale de la "South Church " 88 , mais aussi pour le lien de ces pièces d'habitation avec l'église située immédiatement au nord. Celle-ci reste apparemment en usage pendant toute la période considérée et, pendant le deuxième quart du $\mathrm{IX}^{\mathrm{e}}$ siècle, accueille une crypte richement peinte ${ }^{89}$; un atrium avec des sépultures - au moins en partie très soignées et dont certaines féminines - se greffe contre sa façade (fig. 18), en suggérant une fonction funéraire de l'édifice, sans doute au service des patrons du monastère qui pouvaient trouver abri dans le logis tout à côté. 
Fig. 18 - San Vincenzo al Volturno, la " South Church » et la "Crypt Church » pendant le deuxième quart du IX $\mathrm{X}^{\mathrm{e}}$ siècle ; d'après R. HODGES, S. LEPPARD et J. MITCHELL (dir.), San Vincenzo Maggiore and its Workshops, Rome/Londres, 2011, p. 11, fig. 1.8.

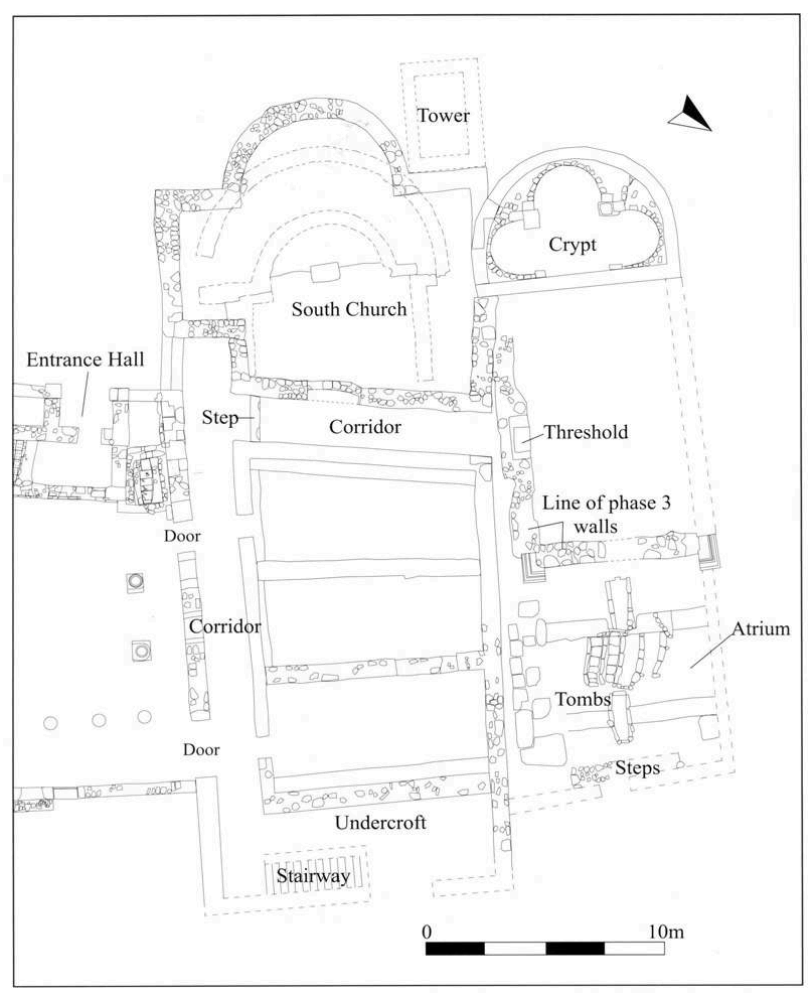

Par ailleurs, l'accès à l'église se fait désormais par l'atrium, tout près du fleuve, et non plus depuis l'intérieur du monastère (à travers le couloir) comme auparavant, ce qui marque le caractère plus « ouvert » du bâtiment ${ }^{90}$.

Selon Richard Hodges et son équipe, pendant la première moitié du $\mathrm{IX}^{\mathrm{e}}$ siècle, d'autres transformations s'imposent également dans la partie méridionale du monastère, où se met en place la construction d'un massif oriental flanquant l'atrium qui précède l'église abbatiale (fig. 19). 
Fig. 19 - San Vincenzo al Volturno. L'église abbatiale et son « eastwork » pendant la première moitié du IX siècle : proposition de phasage (à gauche) et restitution de la porterie, selon $\mathrm{R}$. Hodges ; d'après R. HODGES, S. LEPPARD et J. MITCHELL (dir.), San Vincenzo Maggiore and its Workshops, Rome/Londres, 2011, p. 122, fig. 4.27 et p. 112, fig. 4.19.

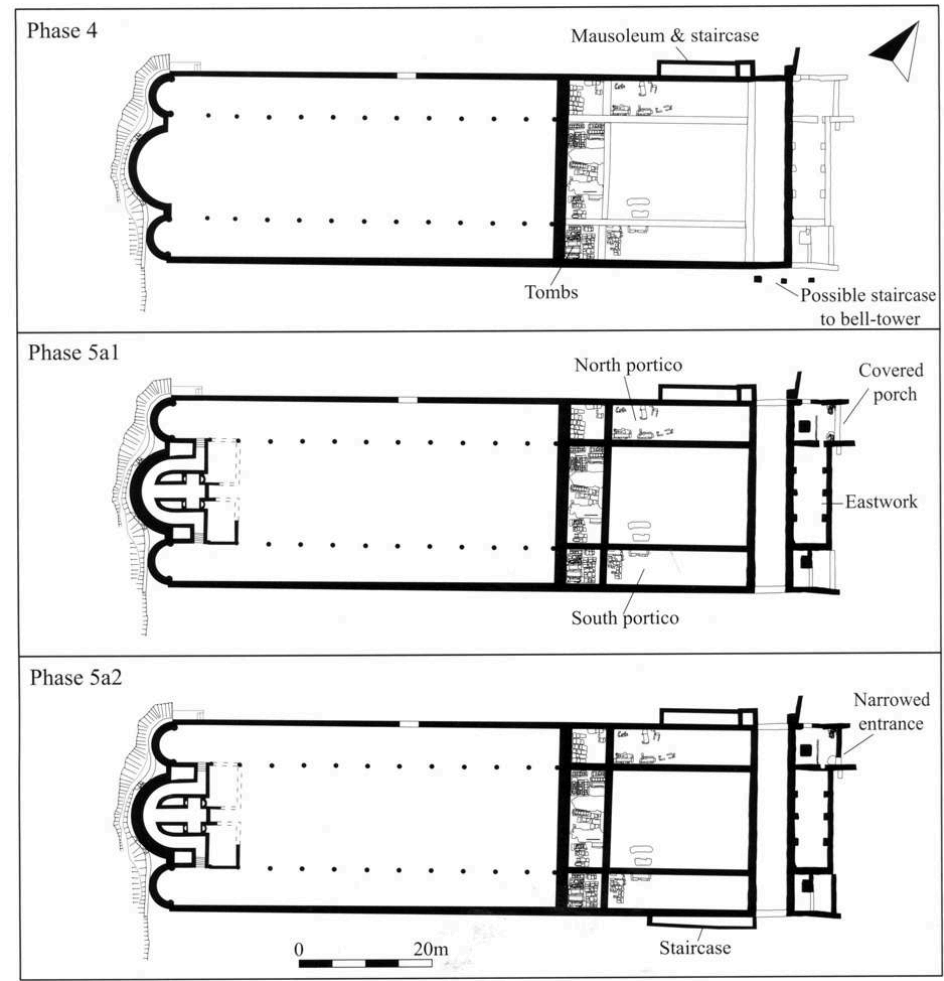

La pièce nord de cet «eastwork» a été identifiée au logis du portier, dans lequel s'ouvrait un escalier menant à l'étage et permettant ainsi l'accès à la galerie est de l'atrium, qui, suivant la conformation du terrain, se trouvait à un niveau plus haut. Audessus de la porte, les fouilleurs anglais ont supposé la présence d'une chapelle, sur la base des nombreux enduits peints retrouvés dans les couches de destruction. Tout cet ensemble serait donc à lire comme un changement d'attitude du monastère par rapport au monde extérieur : en effet, l'accès à l'église abbatiale depuis le fleuve deviendrait de cette façon bien plus important et, surtout, il s'ouvrirait aux « minor guests ", d'après la proposition de Hodges ${ }^{91}$.

61 Cette interprétation pourtant, comme on le sait, a été refusée in toto par les fouilleurs italiens guidés par Federico Marazzi, qui place la réalisation de l'atrium et de sa façade monumentale - avec une organisation différente de celle reconstruite par Hodges, sans aucune chapelle (fig. 20) - pendant l'époque ottonienne ${ }^{92}$. 
Fig. 20 - San Vincenzo al Volturno, restitution des phases du IX (à gauche) et du XI ${ }^{\mathrm{e}}$ siècle (à droite), selon F. Marazzi ; d'après F. MARAZZI, La « basilica maior » di San Vincenzo al Volturno (scavi 2000-2007), Cerro al Volturno, 2014, p. 303, pl. cl et p. 308, pl. clv.

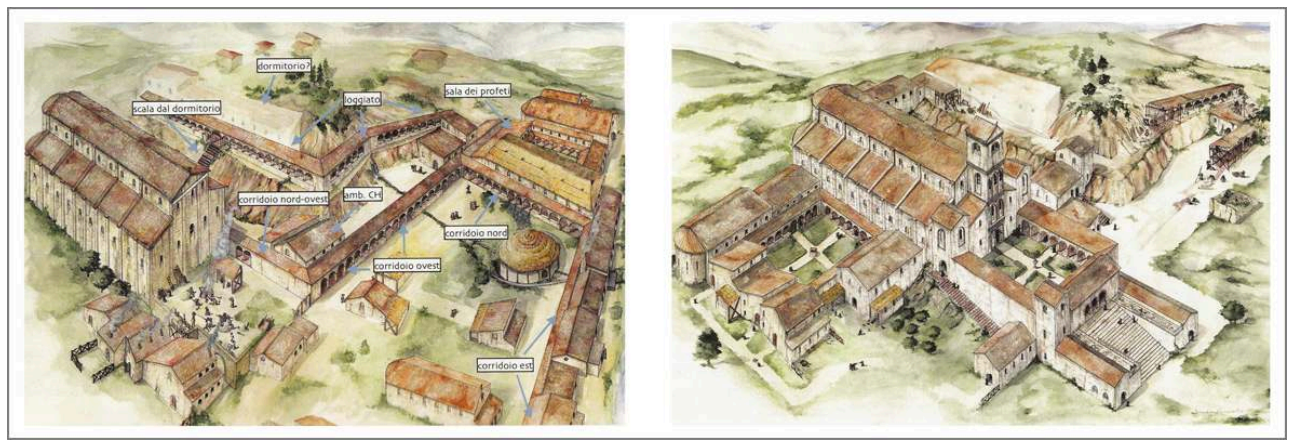

\section{Observations conclusives}

62 type d'assistance et à l'intention de quelle/s catégorie/s d'hôtes? - n'implique pas nécessairement de support spirituel « organisé ", se traduisant systématiquement dans la réalisation d'édifices cultuels dévoués à ce but et à l'usage exclusif des hôtes. Les hospitalia des monastères peuvent être dépourvus d'une chapelle, comme semble être le cas de Nonantola, mais comme le témoigne aussi le plan de Saint-Gall, qui pourtant reproduit plusieurs secteurs destinés aux pauvres, aux pèlerins et aux hôtes de marque, sans qu'un seul de ceux-ci dispose d'une église propre. 
66 Face à ce problème, une démarche possible est fournie par l'interprétation du monasterium au sens large du terme, que l'on vient d'évoquer, en tant qu'unité spatiale qui dépasse l'aire de clôture stricte tout court et dans laquelle le rapport «centre »/ " périphérie » joue un rôle central. L'absence d'une ou de plusieurs églises liées à l'accueil peut sans aucun doute suggérer que, dans certains cas, ce soit l'église abbatiale qui est remplie cette fonction.

La proximité des structures d'accueil de l'abbatiale peut plausiblement attester la pratique, notamment pour les hôtes de marque, de se servir de l'église principale pendant leur permanence au monastère et de participer aux offices. Quand, pendant la seconde moitié du $\mathrm{xl}^{\mathrm{e}}$ siècle, Didier, l'abbé du Mont-Cassin, reconstruit plusieurs édifices de l'ensemble monastique - d'après la Chronica de Léon Marsicanus -, il fait bâtir un xenodochium maximum ad susceptionem peregrinorum à l'extérieur et tout près de la porte, le long de la pente qui mène au claustrum, tandis que, à l'intérieur de celui-ci, il intervient sur la domum... illam, que non competenti loco prope basilicam a parte aquilonali ad xenodochium olim constructa fuerat, en la reconstruisant ampliorem et pulchriorem ${ }^{93}$. Il s'agit donc d'un édifice près de l'abbatiale, qui, au moins au temps de sa reconstruction (mais plausiblement déjà avant), semble accueillir des personnages de rang: un manuscrit un peu plus tardif relate en effet une autre version du texte, où est employé le terme palatium pour qualifier ce nouveau bâtiment, en suggérant qu'il s'agisse de l'hôtellerie ${ }^{94}$.

68 Ces considérations se recoupent évidemment avec le problème majeur de la réelle accessibilité de l'abbatiale, qui semble varier de site en site, mais aussi, au sein du même monastère, au fil du haut Moyen Âge, comme le prouve le cas de San Vincenzo al Volturno : ici, au-delà de la chronologie de l'atrium et surtout du " eastwork », l'accès à l'église se fait par le mur gouttereau nord, donc en provenant de l'ensemble affecté aux moines et peut-être aux seuls hôtes de marque, puisque l'accès pour les fidèles est impossible jusqu'à la construction des structures à l'est de la façade carolingienne ${ }^{95}$.

69 Le problème des accès et de leur emplacement ne concerne pas seulement l'église abbatiale, mais s'étend également à l'espace monastique et aux chapelles « liminales ", qui semblent souvent placées en rapport avec les ouvertures dans l'enceinte ou tout près de la porte, dans un espace intermédiaire entre le claustrum et le monde extérieur. Encore une fois, pourtant, l'absence de traces archéologiques de l'enceinte dans la plupart des monastères italiens rend difficile la compréhension des choix topographiques accomplis à l'occasion de la mise en place de la «fabrique monastique $"{ }^{96}$, dans ses différents états.

70 En même temps, il faut prendre en compte qu'on ne dispose que très rarement de données sur l'environnement des monastères, autour desquels des vrais «bourgs » se forment, des réalités qui interagissent avec l'institution religieuse. Dans ce contexte, encore une fois, les lieux - et notamment les édifices cultuels - en lisière de l'espace monastique occupent une position intermédiaire remarquable, même dans la perspective de la réception des gens provenant de l'extérieur.

71 Ces observations introduisent un autre point essentiel, portant sur les différentes formes d'assistance pratiquées au sein des monastères, qui ont évidemment plusieurs issues au point de vue fonctionnel et topographique ainsi qu'architectural. On ne veut pas rentrer ici dans une question très vaste, si ce n'est pour souligner que la fonction cultuelle de ces bâtiments peut être interprétée de façon différente et avec plusieurs nuances. Ces églises - nommées ecclesiae dans la majorité des cas ici considérés - sont 
souvent associées à un édifice - dit domus dans les chroniques de Novalaise ou du MontCassin, par exemple -, affecté aux hôtes - qu'ils soient de marque ou des simples pauperes et peregrini - et qui représente le lieu de l'accueil « matériel », où l'on reçoit le repas et souvent le logis.

Dans d'autres cas, ces églises jouent pourtant un rôle plus complexe, en devenant un point de repère spirituel essentiel, notamment pour les femmes : celles-ci, ne pouvant se rapprocher du claustrum - et dans plusieurs cas d'une église abbatiale « ouverte » aux laïques - ne sont pas nécessairement des indigentes ou des mulieres venues de loin. Elles peuvent aussi bien être des femmes du coin, de plus en plus attirées par la renommée de reliques vénérées dans le monastère et par la sainteté de la communauté. Dans ce cas, au-delà de la présence de structures liées à l'assistance matérielle, c'est l'accueil spirituel qui devient l'élément principal et qui fait que, dans certains cas de figure, comme à Bobbio, l'église «des femmes" est également associée à une fonction sacramentelle.

Lieux d'assistance spirituelle pour les différentes catégories d'hôtes, signes puissants dans le "paysage monastique » dont les "frontières » sont souvent marquées par ces bâtiments, points clé où le monde des moines rencontre le saeculum, ces églises participent en même temps des changements des espaces d'accueil, qui, notamment depuis l'époque carolingienne, se spécialisent davantage. On les trouve parfois associées à l'hospitale nobilium, comme Richard Hodges et son équipe l'ont proposé pour San Vincenzo al Volturno, où, dans les cas des abbayes placées directement sous la protection impériale comme Farfa, desservant le palatium pour l'empereur en visite.

Elles accompagnent parfois les transformations de la fonction d'accueil au sein des monastères au fil des siècles. C'est le cas du xenodochium de l'abbaye Santa Scolastica à Subiaco, que l'abbé Jean V (1062-1121) fît bâtir iuxta monasterii ianuam et dont le Chronicon sublacense du XVII siècle - mais d'après des documents bien plus anciens fournit une description très efficace. L'édifice résume en soi les fonctions de valetudinarium pro languentium pauperum, au rez-de-chaussée, et d'espace d'accueil ad peregrinorum (...) atque hospitum susceptiones, abrités dans des cubicula à l'étage. À côté de la porte du bâtiment (iuxta valvas xenodochii), et dans le plus strict lien avec celui-ci - un lien qui est à la fois topographique et symbolique -, s'élève l'ecclesiam (...) exiguam, consacrée en 1075 sous le titre de Sancta Maria Nova et pourvue d'un clocher ${ }^{97}$. Un exemple tardif et à la limite de la période ici considérée, qui confirme pourtant une fois de plus, si besoin, le rôle joué par ces églises dans la vie liturgique du monastère, dans le cadre d'un rapport complémentaire avec l'abbatiale - plus ou moins éloignée dans l'espace - et dans un contexte où l'assistance, matérielle et spirituelle, représente un élément incontournable pour l'identité même de la communauté.

\section{NOTES}

1. L'article a été soumis à une révision anonyme, selon le système « double-blind peer review ». 
2. Dans la vaste bibliographie disponible sur ce sujet on se limite ici à la citation des ouvrages incontournables: É. LESNE, Histoire de la propriété ecclésiastique en France, t. 6 (Les églises et les monastères, centres d'accueil, d'exploitation et de peuplement), Lille, 1943 ; J. MOLLAT (dir.), Études sur l'histoire de la pauvreté, Paris, 1974. Plus récemment, on signale : F.-O. TOUATI (dir.), Archéologie et architecture hospitalières de l'Antiquité tardive à l'aube des temps modernes, Paris, 2004 ; P. MONTAUBIN (dir.), Hôpitaux et maladreries au Moyen Âge : espace et environnement, Amiens, 2004 ; E.-R. LABANDE, Pauper et peregrinus. Problèmes, comportements et mentalités du pèlerin chrétien, Turnhout, 2004 ; J.W. Brodman, Charity and Religion in Medieval Europe, s. 1., 2009. Sur l'Orient tardoantique on renvoie à : A. T. CRISLIP, From Monastery to Hospital. Christian Monasticism and the Transformation of Health Care in Late Antiquity, 2005. Pour la question spécifique des xenodochia et la situation italienne, voir : W. SHÖNFELD, « Die Xenodochien in Italien und Frankreich im frühen Mittelalter », in Zeitschrift der Savigny. Stiftung für Rechtsgeschichte, 12 (1922), p. 1-54; et, en considérant la bibliographie plus recente, F. R. STASOLLA, « A proposito delle strutture assistenziali ecclesiastiche : gli xenodochi », in Archivio della Società Romana di Storia Patria, 121 (1998), p. 5-45, avec références précédentes. Sur ces problèmes, en particulier pour ce qui concerne les sources écrites et matérielles de l'Italie au haut Moyen Âge, je me permets de renvoyer aux interventions que j'ai tenu aux journées d'études de Tours (17 octobre 2012), Les espaces d'accueil en contexte monastique de l'antiquité tardive à l'époque moderne («Les lieux d'accueil dans les monastères en Italie du nord et dans l'arc alpin: sources écrites et matérielles»); Paray-le-Monial (29-30 septembre 2012), Tableaux de la vie monastique: "les travaux et les heures" ("Que les hôtes soient reçus comme le Christ" : espaces d'accueil dans les monastères du haut Moyen Âge ») ; Lyon (8 février 2013), Les structures d'accueil et d'hébergement dans les monastères du haut Moyen Âge au $\mathrm{XVI}^{e}$ siècle («Conclusions ») [http.//calenda.org/234152]; Einsiedeln (3-6 septembre 2014), Nach Rom gehen. Monastische Reisekultur im Mittelalter («Monaci, monasteri e strutture di ospitalità nell’Italia altomedievale ») ; ainsi qu'à mon article «Structures d'accueil et monastères : sources écrites et sources archéologiques entre les Alpes et l'Italie centrale au haut Moyen Âge ", à paraitre dans les actes du colloque de l'IFAO : La vie quotidienne des moines en Orient et en Occident, IV $V^{e}-X^{e}$ siècle, II, Questions transversales (Paris, 21-23 novembre 2011). Un ouvrage de synthèse sur ces thèmes est en préparation.

3. Voir dans ce volume l'article de M. Gaillard.

4. C. MANARESI (éd.), I placiti del Regnum Italiae, I (Fonti per la Storia d'Italia, 92-I), Rome, 1955, doc. 49, p. 161-166.

5. G. RABOTTI (éd.), Breviarium Ecclesiae Ravennatis (Codice bavaro), secoli VII-X (Fonti per la Storia d'Italia, 110), Rome, 1985, n 69, p. 34 et $n^{\circ} 77$ (68), p. 41.

6. Pour la citation et les questions de terminologie voir: G. CANTINO WATAGHIN, «Concluding Remarks ", in H. DEY et E. FENTRESS (dir.), Western Monasticism Ante Litteram : the Spaces of Monastic Observance in Late Antiquity and the Early Middle Ages, Turnhout, 2011, p. 363.

7. H. DEY, « Diaconiae, xenodochia, hospitalia and monasteries : "social security" and the meaning of monasticism in early medieval Rome ", in Early Medieval Europe, 16 (2008), p. 403-409. D'après cette lecture, le terme xenodochium semblerait indiquer une institution dévouée à la distribution de la nourriture quotidienne aux pauvres et à l'assistance médicale aux malades de la ville ; pas question, donc, d'accueil aux étrangers (en opposition à l'interprétation courante, fondée sur l'étymologie grecque), tandis que les diaconiae auraient eu la tâche de fournir aux pauvres romains ainsi qu'aux étrangers la nourriture et le bain rituel (lusma), une pratique où les aspects hygiéniques se recoupent avec l'idée de la purification spirituelle. L'hospitale aurait lui aussi soulagé les indigents de Rome et également les peregrini, en leur fournissant nourriture et logis. Sur la situation romaine, voir aussi: R. SANTANGELI VALENZANI, "Pellegrini, senatori e papi. Gli xenodochia a Roma tra il V e il IX secolo ", in Rivista dell'Istituto Nazionale di Archeologia e Storia dell'Arte, 19-20 (1996-1997), p. 203-226 ; L. PANI ERMINI (dir.), Christiana loca. Lo spazio cristiano nella 
Roma del primo millennio, Rome, 2000, en particulier les contributions de la section «Lo spazio monastico e dell'assistenza», dirigée par A. M. Giuntella; A. M. GIUNTELLA, «Gli spazi dell'assistenza e della meditazione ", in Roma nell'alto medioevo, Spolète, 2001, p. 639-691; R. MENEGHINI, « Edilizia pubblica », in R. MENEGHINI et R. SANTANGELI VALENZANI, Roma nell'altomedioevo. Topografia e urbanistica della città dal V al X secolo, Rome, 2004, en part. p. 72-101.

8. H. DEY, « Diaconiae... », ibid., p. 417-418. « This "active" brand of monastic life has yet to receive due recognition, despite several decades' worth of increasing emphasis on the exceptional variety of the forms takes by late antique and early medieval monasticism, much of it focused on varieties of practice that differed from the "cloistered" paradigm which eventually predominated (...) At Rome (...) there was a sizeable stratum of "working monks" upon whom the church depended to perform a number of essential tasks : in addition to charitable activities, we might add the deployment of monks as caretakers and choristers at churches and martyrial shrines throughout the city and its immediate surroundings. » Pour le "carattere monastico di queste strutture ", voir aussi R. MENEGHINI, «Edilizia pubblica...», ibid., p.96. Il faudrait pourtant s'interroger plus en détail sur le statut de ces religieux employés dans l'assistance, ainsi que sur le degré d'application de la vie communautaire auprès d'eux, du respect d'une règle et de l'organisation au sein de ces institutions, même du point de vue des structures matérielles (par exemple la position des lieux où ces fonctions d'assistance sont mises en place par rapport au lieu de vie des religieux). Étant donné la fluidité de la terminologie latine par rapport aux réalités très différentes, peut-être serait-il plus convenable d'éviter, surtout dans ces cas, la traduction dans les langues modernes du mot monasterium.

9. т. TSABó, «Xenodochia, Hospitäler und Herbergen. Kirchliche und kommerzielle Gästung im mittelalterlichen Italien (7. bis 14. Jahrhundert) », in H. C. PEYER et E. MÜLLER-LUCKNER (dir.), Gastfreundschaft, Taverne und Gasthaus im Mittelalter, Munich/Vienne, 1983, en part. p. 66-67.

10. Le phénomène de la pratique ascétique vécue à l'intérieur de sa propre maison est bien connu dès l'Antiquité tardive et il est aussi attesté dans l'Italie du haut Moyen Âge, notamment en relation avec la spiritualité féminine. Sur cette question, voir L. RUDGE, « Dedicated Women and dedicated Spaces : Caesarius of Arles and the foudation of St John », in H. DEY et E. FENTRESS (dir.), Western Monasticism..., op. cit., p. 102-106 (pour la Gaule), et, pour le cas italien, G. CANTINO WATAGHIN, «Istituzioni monastiche nel Friuli altomedievale : un'indagine archeologica », in Paolo Diacono e il Friuli altomedievale (secc. VI-X), Spolète, 2001, p. 286-287.

11. L. schiaparelli (éd.), Codice Diplomatico Longobardo, II (Fonti per la Storia d'Italia 63), Rome 1933, doc. 175, p. 138-141.

12. T. TSABÓ, «Xenodochia... », op. cit., p. 66-67.

13. L. SChiAPARelli (éd.), Codice Diplomatico Longobardo, I (Fonti per la Storia d'Italia 62), Rome, 1929, doc. 28, p. 102-105: Pertuald, en revenant d'un pèlerinage à Rome, donne des biens à l'église Saint-Michel, fondée par lui-même près de sa maison (prope domus cellula mea ubi cummanire videor), et au monasterium se dressant dans le même lieu, où se trouvent abbas vel monachi. Un sacerdus, qualifié aussi de abbas, desservira l'église et s'occupera des veuves, des orphelins, des pauvres et des peregrini, tandis que, à sa mort, la congrecatio pourra élire abbatem et priorem.

14. É. LESNE, Histoire de la propriété..., op. cit., p. 145-146.

15. Pour quelques références concernant le vaste problème des chapelles aux limites de l'espace monastique et des espaces d'accueil au sein de celui-ci, je renvoie à E. DESTEFANIS, «Ad portam monasterii. Accessi e spazi liminari nei monasteri dell'Occidente altomedievale (secoli VI-IX)», in E. DESTEFANis et C. LAMBERT (dir.), Per diversa temporum spatia. Scritti in onore di Gisella Cantino Wataghin, Verceil, 2011, p. 51-84, en part. p. 60-61.

16. D'après la Règle du Maître, deux moines doivent contrôler la cella peregrinorum, située semote in monasterio; de cette façon, si l'un des hôtes veut ad oratorium ire, un des frères pourra 
l'accompagner, tandis que l'autre restera dans le logis avec les autres hôtes, cf. La Règle du Maître, 79, 10, éd. A. DE VOGÜÉ, Paris, 1964 (Sources chrétiennes, 106), t. 1., p. 324). Dans la Règle de saint Benoît, le chapitre 53 prévoit que suscepti autem hospitem ducantur ad orationem, sans que le texte précise le lieu où l'oraison se fait, cf. La Règle de saint Benoît, 53, 7, éd. A. DE VoGÜÉ, Paris, 1972 (Sources chrétiennes, 181), t. 1, p. 612.

17. Concilium aquisgranense a. 816, Institutio sanctimonialium, 28, éd. MGH, Concilia, II, Concilia aevi karolini, 1, 1, Hanovre/Leipzig, 1979, p. 455 (quamquam ad portam monasterii locus talis sit rite habendus, in quo adventantes quique suscipiantur, oportet tamen, ut extra, iuxta ecclesiam scilicet, in qua presbiteri cum ministris suis divinum explent officium, sit hospitale pauperum) ; par contre (p. 456), intra monasterium est prévu un receptaculum, ubi viduae et pauperculae tantummodo recipiantur et alantur. Sur ces aspects voir aussi E. DESTEFANIS, « Ad portam monasterii... », ibid., p. 61.

18. G. P. BROGIOLO et F. MORANDINI (dir.), Dalla corte regia al monastero di San Salvatore-Santa Giulia di Brescia, Mantoue, 2014, avec bibliographie précédente. Sur l'organisation du monastère et ses structures matérielles, demeure l'aperçu très utile de A. BREDA, «Strutture architettoniche e fonti scritte ", in R. STRADIOTTI (dir.), San Salvatore, Santa Giulia di Brescia. Il monastero nella storia, Milan, 2001, p. 133-149.

19. C. zANI, "Lo xenodochio di S. Giulia ", in C. STella et G. BRENTEGANI (dir.), S. Giulia di Brescia. Archeologia, arte, storia di un monastero regio dai Longobardi ai Carolingi, Brescia, 1992, p. 245, avec références ; A. BREDA, « Strutture architettoniche... », ibid., p. 147-148.

20. G. ARCHETTI, «Pellegrini e ospitalità nel medioevo. Dalla storiografia all'ospedale di Santa Giulia di Brescia ", in ID. (dir.), Lungo le strade della fede. Pellegrini e pellegrinaggio nel Bresciano, Brescia, 2001, p. 107-108 et p. 126, note 141.

21. C. ZANI, « Lo xenodochio... », op. cit., p. 248-250 ; G. P. BROGIOLO, Brescia altomedievale. Urbanistica ed edilizia dal IV al IX secolo, Mantoue, 1993, p. 110. La maçonnerie du haut Moyen Âge, en blocs de pierre et fragments de briques alternés à des assises de briques, n'est pas datable avec plus de précision.

22. G. ARCHETTI, « Pellegrini e ospitalità... », op. cit., p. 107 et 126, note 136. L'association explicite de la chapelle avec l'hôpital remonte toutefois à une période très tardive, notamment en 1658 , quand un érudit local, B. Faino, parle de la ecclesia S. Remigij antiquo hospitali S. Juliae adherens (C. ZANI, « Lo xenodochio... », ibid., p. 248).

23. Il suffit de rappeler la dédicace de l'abbatia de Berceto à l'évêque de Reims (attestée pour la première fois en 913), sur les Apennines entre Parme et la Ligurie orientale, le long d'une route de pèlerinage international au haut Moyen Âge. Sur ce cas de figure et la diffusion du culte du saint, on renvoie à : L. CANETTI, «Culti e dedicazioni nel territorio parmense : il dossier bercetano dei santi Moderanno e Abbondio (secoli VIII-X)», in R. GRECI (dir.), Studi sull'Emilia occidentale nel Medioevo : società e istituzioni, Bologne, 2001, en part. p. 76-88 et 100.

24. G. ARCHETTI, «Pellegrini e ospitalità... », op. cit., p. 104. L'ecclesia Santi Andree apostoli que est constructa de foris prope portam civitatis Brixie est mentionnée dans un document de 1126, pour lequel voir: G. ANDENNA, "Il monastero e l'evoluzione urbanistica di Brescia tra XI e XII secolo », in C. STELla et G. BRENTEGANI (dir.), S. Giulia di Brescia..., op. cit., p. 116, note 20. Les expressions hospitale nobilium et hospitale pauperum, ici évoquées, sont celles, bien connues, employées par les sources carolingiennes : voir ci-dessous la note 86 , pour les références principales.

25. C. ZANI, « Lo xenodochio... », op. cit., p. 245, avec références documentaires.

26. G. ARCHETTI, «Pellegrini e ospitalità... », op. cit., p. 106. Voir aussi ID., «Vita e ambienti del monastero dopo il Mille ", in R. STRADIOTTI (dir.), San Salvatore..., op. cit., p. 113 et 129 et A. BREDA, «Strutture architettoniche... », op. cit., p. 134 et 146-147.

27. H. NOIZET, La fabrique de la ville. Espaces et sociétés à Tours (IXe-XIII siècle), Paris, 2007, p. 37.

28. H. NOIZET, La fabrique de la ville..., ibid., p. 38 (en part. fig. 3) et 81. 
29. K. SCHMID, Anselm von Nonantola. Olim dux militum - nunc dux monachorum, Tübingen, 1967 ; R. FANGAREZZI, P. GOLINELLI et A. M. ORSELLI (dir.), Sant'Anselmo di Nonantola e i santi fondatori nella tradizione monastica tra Oriente e Occidente, Rome, 2006, avec bibliographie précédente ; P. GOLINELLI, Nonantola i luoghi e la storia. Guida spazio-temporale di un grande centro monastico e del suo territorio, Nonantola, 2007.

30. Parmi les publications les plus récentes, avec une attention spécifique aux problèmes topographiques, architecturaux et fonctionnels, voir : s. GELICHI et M. LIBRENTI, « Nascita e fortuna di un grande monastero altomedievale. Nonantola e il suo territorio dalla fondazione al XIV secolo ", in F. DE RUBEIS et F. MARAZZI (dir.), Monasteri in Europa occidentale (secoli VIII-XI) : topografia e strutture, Rome, 2008, p. 238-257; S. GELICHI et M. LIBRENTI (dir.), Nonantola, t. 1 (Ricerche archeologiche su una grande abbazia dell'altomedioevo italiano), Florence, 2005 ; F. BERTOLDI et M. LIBRENTI (dir.), Nonantola, t. 2 (Il cimitero bassomedievale della chiesa di San Lorenzo nel Borgo di Nonantola), Florence, 2007 ; M. LIBRENTI et A. CIANCIOSI (dir.), Nonantola, t. 3 (Le terre dell'Abate. Il Nonantolano tra tarda Antichità e Medioevo), Florence, 2011 ; s. GELICHI et M. LIBRENTI (dir.), Nonantola, t. 4 (L'Abbazia e le sue chiese), Florence, 2013. On renvoie à ces contributions et à la bibliographie de référence citée ici pour la situation du monastère au haut Moyen Âge.

31. Respectivement, pour les références documentaires: M. DEBBIA, Il bosco di Nonantola. Storia medievale e moderna di una comunità della bassa modenese, Bologne, 1990, p. 29, notes 33 et 34 ; G. TIRABoschI, Storia dell'augusta badia di S. Silvestro di Nonantola, t. 2, Modene, 1785, doc. $\mathrm{n}^{\circ} 172$, p. 192. En 1064, l'abbé Landolphe donne en precaria à une famille de Nonantola des biens fonciers situés in nominato castro et in burgo ipsius castri, ce qui confirme la présence de l'expansion de l'habitat adossé au castrum monastique (G. TIRABOschI, Storia..., ibid., doc. n 176, p. 195).

32. En particulier voir : s. GELICHI et M. LIBRENTI, « Nascita e fortuna... », op. cit.; M. DEBBIA, La pieve nonantolana di San Michele nei secoli IX-XIII, Nonantola, 1990, p. 174. Ce dernier rappelle l'allusion, dans plusieurs documents, aux casamenta du burgus, qui, d'après leurs limites parcellaires, sont manifestement inclus dans le murum et le fossatum qui protègent l'habitat.

33. Sur l'église : M. DEBBIA, La pieve nonantolana..., ibid.; S. GELICHI, « La pieve di San Michele : storia di una chiesa e storia degli scavi », in s. GELICHI et M. LIBRENTI (dir.), Nonantola, t. 4, op. cit., p. 93-116.

34. L. schiaPARELLI (éd.), I diplomi di Guido e di Lamberto (sec. IX), Rome, 1906, doc. nº 7, p. 109. Sur l'infirmerie du monastère voir : G. SPINELLI, «Ospizi ed ospedali nonantolani », in Ravennatensia X, Cesena, 1984, p. 149-151 (qui suppose l'infirmaria à l'intérieur de l'enceinte monastique).

35. Archive Abbatial de Nonantola, Pergamene, cart. 9, n. 58r. Déjà deux années auparavant, en 1222, l'abbé Raimond, avec la communauté monastique, nomma deux moines chargés de l'administration de l'hospitale et de l'infirmerie (M. DEBBIA, La pieve nonantolana..., op. cit., p. 131, avec références documentaires). Je remercie vivement don Roberto Fangarezzi, directeur de l'Archive, pour le soutien assuré à ma recherche.

36. Archive Abbatial de Nonantola, Protocolli Notarili, 18, charte 42v (actum in burgo de mane castri Nonantulee in hospitali predicto), transcription dans C. CASTAGNETTI, L'ospitalità nel medioevo: il monastero di San Silvestro di Nonantola, thèse, dir. R. Greci, université de Parme, 2001-2002, non publiée (une copie est conservée auprès de l'Archive Abbatial de Nonantola). Si l'on admet l'idée de la persistance de la localisation de l'hôpital au cours du Moyen Âge dans le burgus, la firmaria dont parlent les documents cités n'est pas celle destinée aux moines (à situer vraisemblablement à l'intérieur de l'abbaye), mais il s'agit d'un lieu au service des malades, que le monastère soutien et soigne. Un document de 1270 , rédigé sub porticu palatii foresteriorum, fait peut-être allusion à un autre bâtiment dévoué à l'accueil des étrangers, avec une fonction d'hôtellerie proprement dite, cf. G. TIRABOSCHI, Storia..., op. cit., t. 1, 1784, p. 188. Néanmoins, la prudence dans l'interprétation s'impose, parce que quelques décennies plus tard, en 1295, un autre document est rédigé sub porticu palatii forensium (ibid.), terme qui est employé dans les sources du bas Moyen Âge pour indiquer les habitants dont la famille n'est pas originaire de Nonantola. 
37. Vita Anselmi abbatis nonantulani, 4, éd. MGH, Scriptores Rerum Langobardicarum et Italicarum saec. VI-IX, Hanovre, 1878, p. 568 : hospicia atque scenodochia perplura constituere curavit (...) quorum unum prope monasterium fere quatuor miliaria statuit, ubi oraculum sancti Ambrosii ad suscipiendos debiles et feminas, qui ad monasterium venire non poterant, constituit, cui in omnibus tanta concessit bona necessitatibus, ut nichil deerat ibi servientibus neque supervenientibus hospitibus.

38. G. TIRABoschi, Storia..., op. cit., t. 2, doc. $n^{\circ}$ 203, p. 217 (synode de 1101, liste des prêtres des églises dépendantes de la plebs de Nonantola : de Sancto Ambrosio); doc. n 368, p. 317 (a. 1188 : ecclesiam S. Ambrosii). Sur l'église, voir aussi : G. SPINELLI, « Ospizi... », op. cit., p. 137 ; C. CASTAGNETTI, L'ospitalità..., op. cit., p. 117.

39. P. MUCCI et E. TROTA, "La strada medievale fra Nonantola e la Toscana ", in Viabilità antica e medievale nel territorio modenese e reggiano. Contributi di studio, Modène, 1983, p.35-89, en part. p. 43-52 pour l'hospice de Saint-Ambroise.

40. C. Cipolla (éd.), Codice diplomatico del Monastero di Bobbio fino all'anno 1208, t. 1, doc. $\mathrm{n}^{\circ}$ 3, p. 89 (a. 613 environ).

41. F. MAZEL, «Lieu sacré, aire de paix et seigneurie autour de l'abbaye de Saint-Gilles (fin IX début XIII ${ }^{\mathrm{e}}$ siècle) ", in Lieux sacrés et espace ecclésial (IXe-XVe siècle), éd. Cahiers de Fanjeaux, 46 (2011), p. 239, avec autre bibliographie. Sur ces aspects, je me permets de renvoyer dernièrement à mon article « Monasteri, poli devozionali e abitato : riflessioni sui "borghi monastici" di età medievale dell'Italia settentrionale, tra fonti scritte e strutture materiali », in P. DE VINGO (dir.), In ricordo di Marilli. Miscellanea di studi in ricordo di Maria Maddalena Negro Ponzi, Alexandrie, sous presse.

42. G. SPINELLI, « Ospizi... », op. cit.

43. Sur le monastère: M. G. CERRI (éd.), Novalesa, nuove luci dall'Abbazia, Milan, 2004 et, en particulier pour le contexte de sa fondation, G. SERGI, « Novalesa fra storia e storiografia », M. G. CERRI (éd.), Novalesa..., ibid., p. 21-33.

44. G. C. ALESSio (éd.), Cronaca di Novalesa, Turin, 1982, II, 2, p. 60 (domus, in qua hospitabantur omnes femine, quae ad adorandum Deum ibi veniebant).

45. G. CANTino WATAGHin, "L'abbazia dei Santi Pietro e Andrea di Novalesa: il contributo delle indagini archeologiche al recupero della sua memoria ", in M. G. CERRI (éd.), Novalesa..., op. cit., p. 38. Pour un aperçu sur les structures matérielles de l'abbaye au haut Moyen Âge, on renvoie, en général, à cet article ainsi qu'à : G. CANTINO WATAGHIN, «L'abbaye de Novalaise. Son établissement matériel, au fil de son histoire ", in M. LAUWERS (dir.), Topographie, circulations et hiérarchie au sein des ensembles monastiques dans l'occident médiéval, Actes de la table ronde tenue à Nice, 18-19 avril 2008), Turnhout, sous presse.

46. G.CANTINO WATAGHIN, «L'abbazia di Novalesa nell'alto medioevo: qualche precisazione, a proposito di un articolo recente », in Antiquité Tardive, 13 (2005), en part. p. 416.

47. G. C. Alessio (éd.), Cronaca..., op. cit., II, 2, p. 60.

48. J. M. H. SMITH (trad. Fr. de S. LEBECQ et D. IOGNA-PRAT), «L'accès des femmes aux saintes reliques durant le haut Moyen Âge ", in Médiévales, 40 (2001), p. 83-100 [voir aussi http://www.persee.fr/ web/revues/home/prescript/article/medi_0751-2708_2001_num40_1513].

49. GREG. TUR., Liber vitae patrum, I, 6, éd. B. KRUSCH, MGH, Scriptores Rerum Merovingicarum, I, 2, Hanovre, $1969^{2}$, p. 217 ; Vita patrum Juriensium, 25 et 60-61, F. MARTINE (éd.), t. 1, Paris, 1968 (Sources chrétiennes, 142), p. 266 et 304-306.

50. J. M. H. SMITH, «L'accès des femmes... », op. cit., p. 97.

51. Miracula sancti Columbani, 1, éd. H. BRESSLAU, MGH, Scriptorum, XXX, pars II, Leipzig, 1934, p. 998.

52. M. TOSI, « Un progetto di ricerche e di ripristini per la basilica di San Colombano di Bobbio », in Presenza benedettina nel Piacentino 480/1980, éd. Archivum Bobiense, 1 (1982), p. 40.

53. Sur l'institution du diocèse et les rapports avec le monastère, voir: A. PIAZZA, Monastero $e$ vescovado di Bobbio (dalla fine del X agli inizi del XIII secolo), Spolète, 1997 et maintenant E. DESTEFANIS 
et P. GUGlielmotti (dir.), La diocesi di Bobbio. Formazione e sviluppi di un'istituzione millenaria, Reti medievali-e book, sous presse.

54. Cette église est d'ailleurs attestée bien avant, notamment : C. CIPOLLA (éd.), Codice diplomatico..., op. cit., t. 1, doc. $n^{\circ} 121$, p. 400 (a. 1065) ; t. 2, doc. n 158, p. 36 (a. 1143), doc. $n^{\circ} 163$, p. 51 (a. 1144) et doc. $n^{\circ} 170$, p. 78 (a. 1153).

55. C. cipolla (éd.), Codice diplomatico..., op. cit., t. 2, doc. $n^{\circ} 311$, p. 346 : et dixit [presbiter Petrocus, scil.] quod ecclesia canonicorum dicitur et apelatur eclesia nova, que per monasterium fuit doctata et hedificata ad hoc, ut mulieres et femine possent ibi recipere batismum et alia eclesiastica sacramenta, pro eo quod in eclesia Sancti Columbani non audent intrare femine magne vel parve nec vive nec mortue, quia magna miracula semper aparere consueverunt in maximum detrimentum illarum feminarum, que in dicta eclesia intrare voluerunt vel intraverunt (...) per illos de monasterio instituebantur et destituebantur presbyteri et clerici in dicta eclesia nova, que plebes monasterii tunc dicebatur, et nunc canonica Bobiensi apelatur.

56. Pour une interprétation différente, qui identifie l'eclesia nova avec la cathédrale (hypothèse qui pose pourtant quelques problèmes), voir: M. TOSI, «Un progetto di ricerche...», op. cit., p. 31-32; A. CALzonA, «La questione dell'ubicazione del San Colombano e della Cattedrale di Bobbio ", in L. VALLE et P. PULINA (dir.) San Colombano e l'Europa. Religione, Cultura, Natura, Côme/ Pavie, 2001, p. 79. Pour une discussion sur l'église nova et les possibles origines du groupe épiscopal de Bobbio, voir: E. DESTEFANIS, «Il nucleo episcopale e l'abitato di Bobbio in età medievale : dinamiche di un rapporto complesso », in E. DESTEFANIS et P. GUGLIELMOTTI (dir.), La diocesi di Bobbio..., op. cit. On attire encore l'attention sur le fait que le texte des Miracula associe à cette église la présence d'une croix qui aurait été fixée ici par le successeur de Colomban, Athala, à laquelle fait également référence Jonas de Bobbio : au-delà du fait que Jonas plaçait la croix à l'extérieur de la cellula de l'abbé, c'est intéressant de retrouver ce signe puissant à côté de l'église mariale des Miracula, un signe qui marque souvent la limite d'un espace sacré, tel qu'on l'observe à Novalaise et par exemple à Grandlieu. Ici, les Miracula sancti Filiberti d'Ermentaire (Vita Filiberti abbatis gemeticensis et heriensis, 69-72, éd. O. HOLDER-EGGER, MGH, Scriptores Rerum Merovingicarum, V, Hanovre/Leipzig, 1910, p. 300), relatent la présence d'une croix in signum longiuscule a forinseca monasterii porta, qui indiquait la limite de l'accès aux femmes.

57. E. DESTEFANIS, Il monastero di Bobbio in età altomedievale, Florence, 2002, p. 5-17.

58. C. cipolla (éd.), Codice diplomatico..., op. cit., t. 1, doc. $n^{\circ} 121$, p. 400 (a. 1065) ; t. 2, doc. $n^{\circ} 158$, p. 36 (a. 1143), doc. $n^{\circ} 163$, p. 51 (a. 1144) et doc. $n^{\circ} 170$, p. 78 (a. 1153).

59. F. G. NUVOLONE, «Il Sermo de Charitate Dei ac proximi e il contesto ospedaliero bobbiese : edizioni e spunti analitici (II)», in Archivum Bobiense, 5 (1983), p. 145. On renvoie à cet article pour un aperçu sur l'histoire hospitalière de Bobbio au Moyen Âge (en part. p. 119-167).

60. Cette hypothèse a été émise par M. GAZZINI, «La rete ospedaliera di Bobbio fra alto e basso medioevo », in E. DESTEFANIS et P. GUGLIELMOTTI (dir.), La diocesi di Bobbio..., op. cit.

61. C. cipolla (éd.), Codice diplomatico..., op. cit., t. 1, doc. nº 36, p. 141 (Hospitaliarius pauperum recipiat eos et ministret eis et accipiat a portario stipendium eorum).

62. H. BRESSLAU (éd.), Miracula..., op. cit., 7 et 28, p. 1000 et 1014 (malades guéris par le saint qui restent pendant plusieurs années in hospitali, où ils reçoivent la nourriture et le vêtement). La résidence permanente dans cet espace spécialisé du monastère fait penser à ce que l'on connaît pour la matricula, pour laquelle on renvoie à M. ROUCHE, «La matricule des pauvres. Évolution d'une institution de charité de Bas Empire jusqu'à la fin du haut Moyen Âge », in MOLlat (dir.), Études sur l'histoire de la pauvreté..., op. cit., p. 83-110.

63. Les sources écrites plus tardives, datant du bas Moyen Âge, relatent toutefois la présence d'un hôpital et d'une église Sainte-Marie au service des malades et des pauvres, à identifier très vraisemblablement avec l'ensemble dévoué à l'assistance au sein du monastère. Cette église, que l'on peut encore observer aujourd'hui sous le titre de Sainte-Marie-aux-Grâces, dans son état du 
début $\mathrm{XVIII}^{\mathrm{e}}$ siècle, se situait à la limite de l'espace monastique, au sud de l'abbatiale actuelle et des anciens bâtiments conventuels. Elle est mentionnée tout simplement comme Sainte-Marie (bien qu'indirectement par le biais du nom de l'hôpital) depuis le début du $\mathrm{xv}^{\mathrm{e}}$ siècle, quand le pôle charitable donne aussi le nom à une rue (in contracta hospitalis sancte Marie) et apparaît en tout cas déjà passé sous le contrôle de l'évêque. Voir : F. G. NUvolone, « Il Sermo de Charitate... », op. cit., p. 142-146 (pour les mentions du $\mathrm{Xv}^{\mathrm{e}}$ siècle). Dans les années quatre-vingt-dix du $\mathrm{Xv}^{\mathrm{e}}$ siècle, est rattachée à l'église et à l'hôpital la confrérie des Disciplinati. La S. Maria Gratiarum ecclesia est le premier lieu de station liturgique du clergé de la ville après la cathédrale, pendant la feria secunda in rogationibus, selon le processionnel conservé aux Archivi Storici Diocesani de Bobbio, ms. 10, daté 1627, mais sans doute remontant à 1459. Voir maintenant: L. SCAPPATICCI, «I libri della cattedrale di Bobbio. Studio e ricognizione della biblioteca secolare con un catalogo in appendice », in E. DESTEFANIS et P. GUGLIELMOTTI (dir.), La diocesi di Bobbio..., op. cit.

64. A. DIERKENS, Abbayes et chapitres entre Sambre et Meuse (VII ${ }^{e}-\mathrm{XI}^{e}$ siècle). Contribution à l'histoire religieuse des campagnes du haut Moyen Âge, Sigmaringen, 1985, p. 315-317, avec références documentaires. Une église mariale en marges de l'espace monastique, éloignée d'environ $300 \mathrm{~m}$ de l'abbatiale, est bien connue aussi à Centula. Pour ses structures matérielles, cf. H. BERNARD, "Saint-Riquier, fouilles et découvertes récentes", in C. SAPIN (dir.), Avant-nefs et espaces d'accueil dans l'église entre le IV et le XII siècle, Paris/Auxerre, p. 88-91 et tout récemment: H. BERNARD, "Saint-Riquier : l'abbaye carolingienne d'Angilbert », in A. MAGNIEN (dir.), Saint-Riquier. Une grande abbaye bénédictine, Paris, 2009, p.55-82, part. p.57-60. Sur Lobbes: A. DIERKENS, Abbayes et chapitres..., ibid.

65. Sur l'histoire de l'abbaye au Moyen Âge, au-delà des classiques : I. SCHUSTER, « Reliquie d'arte nella badia imperiale di Farfa», Archivio della R. Società Romana di Storia Patria, 34 (1911), p. 269-350 (qui se concentre sur le problème des espaces d'accueil) et ID., L'imperiale abbazia di Farfa. Contributo alla storia del ducato romano nel medioevo, Rome, 1921, en se tenant aux contributions les plus récentes: M. STROLL, The medieval abbey of Farfa. Target of Papal and Imperial Ambitions, Leiden/New York/Cologne, 1997 ; R. DONDARINI (dir.), Farfa abbazia imperiale, Negarine di S. Pietro in Cariano, 2006 ; S. BOYNTON, Shaping a Monastic Identity. Liturgy and History at the Imperial Abbey of Farfa, 1000-1125, Ithaca/Londres, 2006; M. COSTAMBEYS, Power and patronage in Early Medieval Italy. Local Society, Italian Politics and the Abbey of Farfa, c. 700-900, Cambridge, 2007.

66. Destructio monasterii farfensis edita a domno Hugone abbate, éd. U. BALZANI, Il Chronicon farfense di Gregorio di Catino, I, Rome, 1903, p. 30.

67. C. BRÜHL (éd.), Codice diplomatico longobardo, IV/1, Rome, 1981, doc. $n^{\circ} 8$, p. 22-23. Le texte est un peu ambigu, en mentionnant tout d'abord une via et peu après l'expression per vias, peut-être en laissant entrevoir une multiplicité de points d'intersection entre plusieurs viae se dirigeant vers le monastère et les limites du territoire abbatial : nullam habeant amodo licentiam ambulandi nisi per viam que Salaria est, a Sancto Pancratio recte in pontem Sancti Viti in Sala et exinde in Textam, de Texta in Scappligiano : per vias istas antiquas habeant mulieres licentiam ambulandi.

68. L'identification des lieux n'est pas facile, mais on trouve quand même quelques points de repère : la via Salaria indiquée dans le document est en réalité un embranchement de la Salaria principale, qui, en laissant celle-ci à la hauteur de Viconovo, se dirige vers l'Ombrie (Terni e Rieti) ; sur la question voir : M. L. MANCINELLI, Il «Registrum omnium ecclesiarum diocesis sabiniensis » 1343. Una fonte per la conoscenza della topografia ecclesiastica della Sabina medievale, Rome, 2007, p. 47, avec bibliographie. Pour l'église Saint-Pancrace, une localisation juste au nord-est de ce parcours est envisageable (M. L. MANCINELLI, Il « Registrum..., ibid., p. 217), mais on pourrait aussi émettre l'hypothèse d'une localisation plus au nord de Farfa, le long du morceau " haut » de la via, en imaginant la perspective du duc lombard, qui « regarde » idéalement ce territoire depuis les régions lombardes situées au nord de Farfa et notamment de Spolète. Au nord de l'abbaye, on peut en effet situer plusieurs églises avec cette dédicace : en particulier, on en retrouve une dans 
le Rationale de 1343, dépendant de l'église Saint-Donat de Agellis (M. L. MANCINELLI, Il « Registrum..., ibid., p. 109), qui étend sa juridiction sur le territoire compris entre les rivières Farfa (au nord) et Riana (au sud, tout près de l'abbaye) et également intéressé par la présence des limites du monastère Sainte-Marie. L'emplacement de l'église Saint-Guy (Sanctus Vitus) in Sala est assez bien connu, tout près de l'actuel Ponte Granica, qui permet de traverser Farfa en direction de l'abbaye (M. L. MANCINELLI, Il « Registrum..., ibid., p. 217), tandis que la localité Scappligianum a été localisée à environs $1 \mathrm{~km}$ au sud-ouest du monastère, près de Scaccialupo (E. MIGLIARIO, Strutture della proprietà agraria in Sabina dall'età imperiale all'alto medioevo, Florence, 1988, p.95). Je remercie Maria Letizia Mancinelli pour les informations ponctuelles sur la topographie de ce territoire et pour l'échange bibliographique.

69. Peut-être faut-il songer à une zone près de la ligne des anciens termini ou petrae fictae de l'abbaye, attestés dans les documents depuis le XI ${ }^{\mathrm{e}}$ siècle (par exemple : I. GIORGI et U. BALZANI (éd.), Il regesto di Farfa compilato da Gregorio di Catino, t. 4, Rome, 1892, doc. $\mathrm{n}^{\circ} 611$, p. 9, a. 1011). L'usage pour l'accueil de cette zone à la limite du territoire abbatial est attesté pour la fin du Moyen Âge, comme le documente la Divisio Mensarum du $1^{\mathrm{er}}$ août 1477, qui enregistre : a secundo [latere, scil.] Aqua Salsa usque ad crucem montis Sancti Blasii, a tertio via qua itur usque ad locum qui dicitur Postmontem [actuel Torre Baccelli] usque ad dictam crucem supra prata et hospitale. La croix SaintBlaise est bien localisée par la cartographie de l'époque moderne, à l'ouest de l'abbaye, dont elle marquait un terminus, juste où l'ancienne route provenant de Rome rentrait dans le territoire abbatial, voir : T. LEGGIO et R. LORENZETTI, Le carte di Farfa. Le carte topografiche del territorio di Farfa (secc. XVIII-XIX), Farfa, 1998, carte ${ }^{\circ} 11$, n. XXXVII. Je remercie Luchina Branciani pour ces références et je renvoie également à L. BRANCIANI, «Il monte S. Martino in Sabina. Siti archeologici e storia ", in Eremitismo a Farfa: origine e storia. Per una ricostruzione archeologico-ambientale del complesso eremitico del Monte S. Martino in Sabina, Farfa, 2000, p. 31-133.

70. Destructio monasterii farfensis..., op. cit., p. 30.

71. I. GIORGI et U. BALZANI (éd.), Il regesto di Farfa..., op. cit., t. 2, doc. $n^{\circ} 75$, p. 72.

72. I. GIORGI et U. BALZANI (éd.), Il regesto di Farfa..., ibid., t. 4, doc. nº 1320, p. 314.

73. En 1577-1578, le cardinal Farnèse, abbé commanditaire de Farfa, accepte de transformer une étable située avanti la piazza del Palazzo [du commanditaire, scil.] sotto l'ospedale, e fenile delli Monaci, pour la construction de la douane, cf. Archive de Farfa, 291 A 236, ms. 177, Catalogus cardinalium abatum farfensis, cité dans M. VALENTI, "Il complesso abbaziale", in Farfa, storia di una fabbrica abbaziale, Rome, 2006, p. 65. Ce bâtiment apparaît dans une gravure conservée à l'Archive du monastère (Raccolta piante ; reproduction dans T. LEGGIO et R. LORENZETTI, Le carte di Farfa..., op. cit., p. 17, $\mathrm{n}^{\circ} 10$ ), sous le titre de Dichiarazione dell'elevato del Monastero e Chiesa di Farfa con le Strade, Case e Botteghe della Fiera, datée (mais avec quelques réserves) 1680 (voir ibid., p. 51). En tout cas, cette situation est déjà l'issue d'une série de reconstructions, puisque, quelques années auparavant, en 1566, le même abbé commanditaire recommanda d'accueillir les pauvres in hospitali quod denuo construatis, en faisant ainsi allusion au moins à des remaniements de la structure si non à une vraie reconstruction (I. SCHUSTER, « Reliquie d'arte... », op. cit., p. 286).

74. I. SCHUSTER, « Reliquie d'arte... », ibid., p. 295-296.

75. I. GIORGI et U. BALZANI (éd.), Il regesto di Farfa..., op. cit., t. 4, doc. $n^{\circ} 607$, p. 6 (a. 1010), doc. $n^{\circ} 623$, p. 21 (a. 1012). L'église est également mentionnée dans d'autres documents contemporains, où elle est dite infra monasterium/in monasterio, cf. I. GIORGI et U. BALZANI (éd.), Il regesto di Farfa..., ibid., t. 4 , doc. $n^{\circ} 609$, p. 8 (a. 1011), doc. $n^{\circ} 625$, p. 22 (a. 1012). À la fin du siècle, elle a disparu et à sa place se trouve une cour, cf. I. GIORGI et U. BALZANI (éd.), Il regesto di Farfa..., ibid., t. 5, doc. nº 1144 (a. 1096 ou 1098) : intro ipsa curte ubi etiam fuit cecclesia sancti Petri.

76. Cela pourrait être le cas de l'église Saint-Benoît dite infra ipsum coenobium, où Gemma vient faire une refutatio des biens fonciers au monastère, aussi bien que de l'église Sainte-Croix, située intus in monasterium sanctae Dei genitricis, face à la porte de laquelle Bona accomplit le même geste, 
cf. I. GIORGI et U. BALZANI (éd.), Il regesto di Farfa..., ibid., t. 3, doc. n 433, p. 146 (a. 999) et t. 4, doc. $\mathrm{n}^{\circ} 851$, p. 247 (a. 1055).

77. Pour l'histoire des fouilles et des études sur les structures matérielles de l'abbaye : T. LEGGIO, «L'abbazia di Farfa : fonti scritte, cultura materiale e strutture edilizie », dans Farfa, storia di una fabbrica..., op. cit., p. 135-146, avec bibliographie. Parmi les contributions les plus significatives pour l'interprétation des résultats des fouilles voir : T. LEGGIO, « Farfa. Problemi e prospettive di ricerca ", in Il territorio, 1/1 (1984) ; L. PANI ERMINI, "L'abbazia di Farfa », in M. RIGHETTI TOSTI-CROCE (dir.), La Sabina medievale, Cinisello Balsamo, 1985, en part. p.42-59 et, plus récemment, C. MCCLENDON, The Imperial Abbey of Farfa. Architectural Currents of the Early Middle Ages, New Haven/ Londres, 1987 ; O. GILKES et J. MITCHELL, « The early medieval church at Farfa : its orientation and date ", in Archeologia Medievale, 22 (1995), p. 343-364 ; F. BETTI, La diocesi di Sabina, Spolète, 2005 (Corpus della Scultura altomedievale, 17), en part. p. 53-64.

78. Cf. la note précédente pour les multiples propositions chronologiques (entre le VIII et le $\mathrm{IX}^{\mathrm{e}}$ siècle) concernant cet ensemble et les structures mises à jour aux alentours.

79. C. MCCLENDON, The Imperial Abbey..., ibid., p. 73. La présence de l'empereur et de son entourage à Farfa au haut Moyen Âge est mentionnée dans les sources écrites: Louis II y séjourna en 872 (MGH, Diplomata karolinorum, IV, Ludovici II diplomata, éd. K. WANNER, Munich, 1994, doc. $\mathrm{n}^{\circ} 57$, p. 179), Otton III en 999 (I. GIORgI et U. BALZANi (éd.), Il regesto di Farfa..., op. cit., t. 3, doc. nº 429, p. 143). Les documents du bas Moyen Âge et de l'époque moderne situent dans cette partie du monastère le palais de l'abbé et ensuite de l'abbé commanditaire (I. SCHUSTER, « Reliquie d'arte... », op. cit., p. 334).

80. Dans le même secteur, immédiatement à l'est, la présence des fondations d'un grand bâtiment à deux étages, pourvu d'un escalier à vis, retrouvées près de la façade de l'église actuelle, et datées de l'époque romane, a fait supposer à Charles Mcclendon l'existence à cet endroit d'une "monumental guesthouse or a gateway of some kind», évidemment, dans le premier cas, une hôtellerie destinée aux hôtes de marque (c. MCCLENDON, The Imperial Abbey..., ibid., p. 107).

81. Parmi la vaste bibliographie archéologique sur l'abbaye, on se limite à signaler: R. HODGES (dir.), San Vincenzo al Volturno 1: the 1980-1986 Excavations (part I), Rome/Londres, 1995 ; ID. (dir.), San Vincenzo al Volturno 2: the 1980-1986 Excavations (part II), Rome/Londres, 1995 ; J. MITCHELL, I. L. HANSEN et C. M. COUTTS (dir.), San Vincenzo al Volturno 3 : the Finds from the 1980-1986 Excavations, Spolète, 2001 ; F. MARAZZI, C. FILIPPONE, P. P. PETRONE, T. GALLOWAY et L. FATTORE, «San Vincenzo al Volturno-Scavi 2000-2002. Rapporto preliminare », in Archeologia Medievale, 29 (2002), p. 209-274 ; R. HODGES, S. LEPPARD et J. MITCHELl (dir.), San Vincenzo Maggiore and its Workshops, Rome/Londres, 2011 ; F. MARAzZI, La "basilica maior" di San Vincenzo al Volturno (scavi 2000-2007), Cerro al Volturno, 2014. Je remercie Federico Marazzi pour les informations qu'il m'a fourni et pour l'échange sur cet ensemble monastique.

82. Pour les résultats des fouilles: R. HODGES, S.J. MITHEN, S. GiBSON et J. MITCHELL, "The "South Church" : a Late Roman Funerary Church (San Vincenzo Minore) and the Hall for Distinguished Guests ", in R. HODGES (dir.), San Vincenzo al Volturno 1..., ibid., p. 123-190. Pour une synthèse finale (avec quelques révisions de l'interprétation), on renvoie à : R. HODGES, «The monastic plan in phases 4 and 5 ", in R. HODGES, S. LEPPARD et J. MITCHELL (dir.), San Vincenzo Maggiore..., ibid., en part. p. 414-415. L'origine tardoantique de cette église est maintenant mise en discussion dans $\mathrm{F}$. MARAZZI, La "basilica maior"..., ibid., p. 338-342.

83. V. FEDERICI (éd.), Chronicon vulturnense del monaco Giovanni, t.1, Rome 1925, p. 204. Voir maintenant la traduction italienne: M. OLDONI (dir.), Chronicon vulturnense del monaco Giovanni scritto intorno all'anno 1130, Cerro al Volturno, 2010, p. 133 (trad. L. DE LUCA ROBERTI). 
84. R. HODGES, J. MITCHELl et S. GIBSON, "The Crypt Church", in R. HODGES (dir.), San Vincenzo al Volturno 1..., op. cit., p. 40-74. Sur ce point voir aussi F. MARAZZI, La "basilica maior"..., op. cit., p. 340-341.

85. I. RIDDLER, R. HODGES et J. MITCHELL, "The Garden Court », in R. HODGES (dir.), San Vincenzo al Volturno 1..., ibid., p. 191-209 ; I. RIDDLER, S. GIBSON, R. HODGES et J. MITCHELL, « The Distinguished Guests' Refectory ", in R. HODGES (dir.), San Vincenzo al Volturno 1..., ibid., p. 210-215.

86. L'hôtellerie pour les hôtes de rang est en effet bien attestée dans les sources carolingiennes, comme dans les commentaires de la Règle de saint Benoît (où cette distinction sociale pourtant n'apparaît pas) par Hildemard [R. MITTERMÜLLER (éd.), Expositio regulae ab Hildemaro tradita, Ratisbonae, 1880, cap. 53, p. 506] et Smaragde [A. SPANNAGEL et P. ENGELBERT (éd.), Smaragdi abbatis expositio in Regulam S. Benedicti, Siegburg, 1974 (Corpus Consuetudinum Monasticarum, 8), III, cap. 53, 2, p. 280]. Pour une discussion de ces aspects: M. DE JONG et P. ERHART, «Monachesimo tra $\mathrm{i}$ Longobardi e i Carolingi », in C. BERTELLI et G. P. BROGIOLO (dir.), Il futuro dei Longobardi. L'Italia e la costruzione dell'Europa di Carlo Magno, Saggi, Milan, 2000, p. 123 ; E. DESTEFANIS, Structures d'accueil et monastères..., op. cit., avec bibliographie précédente.

87. F. MARAZZI, La “basilica maior"..., op. cit., p. 342.

88. Selon l'interprétation publiée en 1993, la transformation de l'église, tout en créant une hôtellerie, aurait "sauvé " la partie absidale du lieu de culte, qui aurait continué à être fréquentée, sous la forme d'une chapelle, au service des hôtes ainsi que des pèlerins. Dans la publication de 2011, toutefois, Hodges ne croit plus à cette idée, en pensant que cette partie serait devenue, ainsi que les pièces contiguës, un « undercroft for a floor above it » (R. HODGES, The monastic plan..., op. cit., p. 414). L'autel, abritant des reliques, n'est pourtant détruit que pendant le deuxième quart $\mathrm{du} \mathrm{IX}_{\mathrm{e}}^{\mathrm{e}}$ siècle (par ailleurs avec une certaine attention et de façon systématisée), quand la pièce est remblayée et une nouvelle église, avec une grande abside et un transept, est bâtie au dessus et au lieu de la précédente : tous ces aspects sembleraient laisser entrevoir quand même une permanence de la fonction cultuelle dans le chevet de l'église.

89. F. MARAZZI, La Cripta dell'Abate Epifanio a San Vincenzo al Volturno. Un secolo di studi (1896-2007), Cerro al Volturno, 2013.

90. J. MITCHELl, «The Crypt reappraised », in R. HODGES (dir.), San Vincenzo al Volturno 1..., op. cit., p. 75-76.

91. R. HODGES, S. LEPPARD et J. MITCHELl, "The Atrium and Eastwork », in R. HODGES, S. LEPPARD et J. MITCHELl (dir.), San Vincenzo Maggiore..., op. cit., p. 93-127 ; R. HODGES, The monastic plan..., op. cit., p. 427.

92. F. MARAZZI, La “basilica maior"..., op. cit., p. 147-232 et 329-335.

93. Chronica monasterii casinensis, III, 33, éd. H. HOFFMANN, MGH, Scriptores, XXXIV, Hanovre, 1980, p. 407. Apparemment, pourtant, l'abbé ne déplaça pas le bâtiment, bien que le lieu soit indiqué dans le texte comme inadapté.

94. Dehinc ab aquilonali parte palatium quantitatis non modice ad hospitum quorumque receptionem edificavit (Chronica monasterii casinensis..., ibid.). La position de ce bâtiment (le palatium in quo nobiles quique ospitarentur) est d'ailleurs précisée dans le même texte comme circa atrium maioris ecclesie (Chronica monasterii casinensis..., ibid., IV, 3, p. 469).

95. Sur ce point, voir F. MARAZZI, La “basilica maior”..., op. cit., p. 309-310.

96. L'expression est intentionnellement empruntée à celle de «fabrique urbaine », pour laquelle voir : H. NOIZET, La fabrique de la ville..., op. cit., p. 16-17, avec bibliographie précédente.

97. CHERUBino MIRZIO DA TREVIRI, Chronicon Sublacense (1628-1630), éd. L. BRANCIANI, t. 2, Subiaco, 2014, p. 198 (trad. italienne à la p. 205). Le même texte mentionne aussi le palatium (...) pro nobilium advenientium hospitum susceptione que l'abbé Jean fît bâtir au sein du monastère et qui est dit avoir acueilli l'impératrice Agnès. Il s'agit évidemment de l'hôtellerie pour les hôtes de marque, montrant une architecture très soignée et un haut niveau de confort. Il se présente cum 
deambulacris inferius, superius arcuato opere fornicatum, et perpolito latere quadrato tessellatum eiusque coenacula vitreis finestris illustrata quaeque venusta colorum varietate depicta (...). Ad cuius interius atrium amoenum satis adhcerebat viridarium, ad oblectationem accomodatum in eo pergula (ut dicunt) magis ad voluptatem quam proventum consita erat... (ibid.). Je suis très reconnaissante à Luchina Branciani pour m'avoir indiqué cet important texte.

\section{RÉSUMÉS}

Hospitality for pauperes and peregrini represents a fundamental issue of the monastic life, involving both the material (food, lodging and health) and spiritual care. The study of the charity provided by monasteries is strongly connected with the definition of the monasterium, as in fact in written sources, is often linked to the word xenodochium; furthermore, the monasterium could reach boundaries much wider than the nucleous where monks live.

Just at the edge of this space - the claustrum or a much bigger territory, perceived however as monasterium in every aspect - we can find specific complexes for social (and sometimes medical) services, in certain cases provided with secondary churches, distinct from the abbatial one.

The paper studies, through some Early Middle Ages Italian cases and referring to written as well as archaeological sources, the topographical and functional choices connected to these structures. They appear sometimes thought for specific categories of people, such as women who would not have had access to the claustrum in the male monasteries - or the distinguished guest, who, at least since the Carolingian Age, needed buildings provided with additional comfort.

L'ospitalità verso i pauperes e i peregrini rappresenta un aspetto fondamentale della vita monastica, che coinvolge sia l'assistenza materiale (vitto e talora alloggio e cure mediche) sia quella spirituale. L'analisi delle forme di accoglienza praticate all'interno dei cenobi altomedievali si intreccia con il problema della definizione del monasterium quale entità che viene spesso ricordata dalle fonti scritte in stretta associazione alla termine xenodochium e che può assumere contorni spaziali anche molto più dilatati del nucleo claustrale in senso stretto.

Proprio ai confini di tale spazio - sia esso quello circoscritto intorno al nucleo riservato ai monaci, sia quello ai margini di un territorio ben più ampio, considerato tuttavia monasterium a tutti gli effetti - sorgono spesso i poli destinati all'accoglienza, talora dotati di chiese diverse dall'abbaziale.

L'articolo indaga, attraverso la presentazione di alcuni significativi casi italiani di età altomedievale e facendo riferimento alle fonti scritte e a quelle archeologiche, le scelte topografiche e funzionali legate a tali strutture, talora concepite a servizio di specifiche categorie di persone, come le donne - che non avrebbero avuto altrimenti accesso al claustrum dei monasteri maschili - oppure gli ospiti di alta estrazione sociale, che, almeno a partire dall'età carolingia, necessitavano di spazi di accoglienza dotati di maggiore comfort. 
INDEX

Mots-clés : monastères, hospitalité, xenodochia, hospitalia, églises secondaires

Index géographique : Italie/Brescia, Italie/Bobbio, Italie/Farfa, Italie/Mont Cassin, Italie/

Nonantola, Italie/Novalaise, Italie/Ravenne, Italie/Rome, Italie/San Vincenzo al Volturno, Italie/ Subiaco

\section{AUTEUR}

\section{ELEONORA DESTEFANIS}

Università del Piemonte Orientale « Amedeo Avogadro » 